\title{
Morphology Control of Zinc Electrodeposition by Surfactant Addition for Alkaline-based Rechargeable Batteries
}

Masahiro Shimizu, ${ }^{* \mathrm{ab}}$ Koichi Hirahara, ${ }^{\mathrm{a}}$ and Susumu Arai ${ }^{* \mathrm{ab}}$

${ }^{a}$ Department of Materials Chemistry, Faculty of Engineering, Shinshu University, 4-17-1 Wakasato, Nagano, 380-8553, Japan

${ }^{\mathrm{b}}$ Institute of Carbon Science and Technology, Faculty of Engineering, Shinshu University, 4-17-1 Wakasato, Nagano, 380-8553, Japan

*Corresponding author

Assistant Prof. Masahiro Shimizu

E-mail: shimizu@shinshu-u.ac.jp

Tel: +81-26-269-5627; Fax: +81-26-269-5627

Prof. Susumu Arai

E-mail: araisun@shinshu-u.ac.jp

Tel: +81-26-269-5413; Fax: +81-26-269-5432

Electronic Supplementary Information (ESI) available: XPS spectra, dependence of Zn-deposition behavior and morphologies on applied current density, three-dimensional height profiles, Raman spectra of Zn metal sheets after cycling. See DOI: 10.1039/x0xx00000x.

KEYWORDS: Zn-air battery; Electrodeposition; Dendrite; Mossy; Shape control; Surfactant 


\section{Abstract}

The development of Zn-air batteries with a high energy density of $1350 \mathrm{Wh} \mathrm{kg}^{-1}$ is one of breakthrough required to achieve a low carbon society. However, morphology control of Zn negative electrode during charge/discharge (Zn-deposition/stripping) is essential for the practical application. Considering the manufacturing process, a simple strategy is preferable. Herein, we employed surfactants as an inhibitor of the formation of mossy and dendrite Zn structures, and studied electrochemical Zn growth from the perspective of electric charge of the surfactant. Even by using an additive free electrolyte of $0.25 \mathrm{M} \mathrm{ZnO}+4 \mathrm{M} \mathrm{KOH}$ and with $1 \mathrm{mM}$ sodium dodecyl sulfate (SDS: anionic surfactant) or polyacrylic acid (PAA: non-ionic surfactant), mossy and dendrite formations were unavoidable irrespective of current density. On the other hand, cationic surfactant, trimethyloctadecylammonium chloride (STAC) suppressed the shape change and resulted in smooth and dense morphology. Zeta potential measurements, kinetic current densities observed from Tafel plots, and constant potential electrolysis indicate that quaternary ammonium cations (STAC) with bulky size adsorb to protrusions which are cause of shape change and suppress Zn deposition in the region to promote lateral growth. Although the adsorption of STAC increased an average overvoltage for Zn-deposition/stripping in a symmetric Zn|Zn cell under current density of $10 \mathrm{~mA} \mathrm{~cm}{ }^{-2}$, significantly stable behavior continued during $200 \mathrm{~h}$. In contrast, an overvoltage of an additive free system suddenly increased after $156 \mathrm{~h}$, associated with the accumulation of insulator $\mathrm{ZnO}$ and $\mathrm{Zn}(\mathrm{OH})_{2}$ formed on $\mathrm{Zn}$ surface. In charge-discharge test using an asymmetric $\mathrm{Cu} \mid \mathrm{Zn}$ cell, Coulombic efficiency in an additive free electrolyte was less than 95\%, whereas the addition of STAC with $1 \mathrm{mM}$ achieved superior cycling performance without any capacity loss originated from the generation of dead $\mathrm{Zn}$ (an electrical isolation). These results demonstrate that the addition of STAC is a promising way of controlling Zn morphology. 


\section{Introduction}

While the demand for reducing environmental burden has been increased in recent years, the use of limited fossil fuels continues every day. ${ }^{1}$ For building of a sustainable society utilizing renewable energy effectively, high-performance storage batteries have been required. Zinc-air batteries based on reversible Zn-deposition/dissolution and oxygen-reduction/evolution reactions exhibit a high energy density of $1350 \mathrm{Wh} \mathrm{kg}^{-1}$, which is much larger than those of commercially available Li-ion batteries. ${ }^{2-7}$ The rechargeable batteries can operate under an aqueous-based electrolyte, and therefore the risks of ignition and thermal runaway can be avoided. This is a great motivation in the development. There are, however, two main challenges concerning the morphology control of Zn deposit and the development of catalyst with high activity for oxygen evolution reaction. ${ }^{8-14}$ Focusing on the negative electrode side, $\mathrm{Zn}$ undergoes remarkable shape change during charge-discharge, causing poor cycle performance. At a low current density, electrochemical deposition of Zn results in mossy structure. This is caused by continuous twodimensional nucleation followed by the formation of protrusions on wide terrace and the suppression of microstep growth toward lateral direction. ${ }^{15}$ At a high current density in diffusionlimited condition, dendritic growth is dominant. ${ }^{16}$ Once the undesirable growth such as the formation of mossy and dendritic structures occurs, current density distribution inside electrode is localized, and shape changes develop further with charge/discharge cycling. The generation of the mossy and dendrite structures once undergo, the structures do not disappear and it becomes uncontrollable. The non-uniform Zn morphology prevents homogeneous Zn dissolution (discharge) reaction, which is responsible for deterioration of battery performance. Therefore, the control of Zn deposition morphology is extremely essential. Strategies for the suppression of nonuniform Zn deposition are mainly classified into following five methods; (1) the use of additives 
such as metal-ion and surfactant, ${ }^{12-22}$ (2) the change from aqueous electrolyte to/mixing with an organic electrolyte or an ionic-liquid electrolyte, ${ }^{23-28}$ (3) the optimization of substrate, ${ }^{29}$ (4) the introduction of anion-exchange ionomer between $\mathrm{Zn}$ electrode and electrolyte, ${ }^{30,31}$ and (5) the construction of matrix accommodating shape change. ${ }^{32-34}$ Ohtani et al. reported that $\mathrm{Pb}$ delivered discrete and fine Zn nuclei at the initial stage and mossy structure was suppressed by diminished active growth site. ${ }^{19}$ Endres et al. achieved dendrite-free nanocrystalline Zn deposition from an ionic-liquid electrolyte of $0.1 \mathrm{~mol} \mathrm{dm}^{-3}(\mathrm{M})$ zinc trifluoromethanesulfonate [Zn(OTf $)_{2}$ ]-dissolved in 1-ethyl-3-methylimidazolium trifluoromethanesulfonate (EMI-OTf) with $0.015 \mathrm{M}$ nickel trifluoromethanesulfonate $\left[\mathrm{Ni}(\mathrm{OTf})_{2}\right]$. It was demonstrated that thin $\mathrm{Zn}-\mathrm{Ni}$ alloy film formed on surface at the initial stage by the addition of $\mathrm{Ni}(\mathrm{OTf})_{2}$ allowed the formation of well-defined and uniform Zn. ${ }^{25,26}$ The influence of substrate on Zn electrodeposition was evaluated by Wei et al.; although the use of Sn substrate decreased charge transfer resistance for electrodeposition, Sn corrode in alkaline media. $\mathrm{Ni}$ causes hydrogen evolution to deteriorate $\mathrm{Zn}$ electrode. $\mathrm{Bi}$ and $\mathrm{Cu}$ substrates resulted in low corrosion rate and compact Zn electrodeposition. ${ }^{29}$ Schröder et al. showed the feasibility of $\mathrm{Zn}$ electrode by the introduction of anion-exchange ionomer between $\mathrm{Zn}$ electrode and electrolyte. In that case, the local transformation of $\left[\mathrm{Zn}(\mathrm{OH})_{4}\right]^{2-}$ formed during $\mathrm{Zn}$ dissolution (discharge reaction) in alkaline electrolyte to insoluble $\mathrm{ZnO}$ was mitigated and thereby resulted in the suppression of significant shape change. ${ }^{30}$ Parker and Rolison et al. fabricated threedimensional Zn sponge electrode and the framework maintained monolithic form at various depthof-discharge state, which indicated the possibility of minimization of Zn dendrite inducing shortcircuit. ${ }^{32}$ Considering simplification of the processes, the strategy of use of additive is industrially preferred. The addition of surfactant to an electrolyte is not necessarily a new approach for improving Zn deposition morphology. The new insight in this study is that we found a leveling 
agent enabling to suppress the formation of not only mossy structure but also dendrite structure and highly flatten deposit. In addition, we systematically investigated deposition morphology in wide current densities from 5 to $40 \mathrm{~mA} \mathrm{~cm}{ }^{-2}$, and clarified the relationship between crystal orientation, surfactant concentration, and applied current density. In the present study, we chose anionic, non-ionic, and cationic surfactants as an additive in view from electric charge. Herein, we examined the influence of surfactant on electrochemical $\mathrm{Zn}$ growth behavior and $\mathrm{Zn}$ deposition/stripping properties in an aqueous-based electrolyte. Furthermore, the effect originated from surfactant addition to a Zn negative electrode was evaluated in long-term cycling.

\section{Experimental section}

Zinc oxide $(\mathrm{ZnO})$, potassium hydroxide $(\mathrm{KOH})$, sodium dodecylsulphate (SDS), and polyacrylic acid (PAA, average molecular weight: 5000), and trimethyloctadecylammonium chloride (STAC) were purchased and used further purification. An aqueous-based electrolyte solution (so called alkaline zincate bath) was prepared by dissolving $\mathrm{ZnO}$ powder at a concentration of $0.25 \mathrm{~mol} \mathrm{dm}^{-3}(\mathrm{M})$ in $4 \mathrm{M} \mathrm{KOH}$ aqueous solution $(13.5 \mathrm{~mL})$. We assembled threeelectrode type cells consisted of a Cu substrate $\left(1.7 \mathrm{~cm}^{2}, 18 \mu \mathrm{m}\right.$-thickness; Nilaco Co., Ltd.) as the working electrode, Zn plate (99.99\%; Rare Metallic) as the counter electrode, Zn wire as the reference electrode, and an electrolyte (Figure 1). The $\mathrm{Cu}$ substrate was immersed in alkaline detergent (C-4000; C. Uyemura \& Co., Ltd.) and dilute sulfuric acid at $60{ }^{\circ} \mathrm{C}$ to remove grease in advance. The influence of various surfactant on Zn deposition morphology was examined by confocal laser scanning microscopy (CLSM, VK-8510; Keyence) and field-emission scanning electron microscopy (FE-SEM, JSM-7000F; JEOL Co., Ltd.). Zn-deposition/striping behavior was investigated by galvanostatic charge-discharge tests using an electrochemical measurement 
system (HJ-1001 SM8A, Hokuto Denko Co., Ltd.) and by cyclic voltammetry (CV) measurements though the use of an electrochemical analyzer (SP-200; Bio-Logic Science Instruments) at a sweep rate of $1 \mathrm{mV} \mathrm{s}^{-1}$ at room temperature. The crystal structures of electrolytic deposits were characterized by means of X-ray diffraction (XRD, SmartLab; Rigaku) with $\mathrm{CuK} \alpha$ radiation and X-ray photoelectron spectroscopy (XPS; PHI Quantera II ${ }^{\mathrm{TM}}$, ULVAC-PHI, Inc.) with X-ray (monochromatic radiation $\mathrm{Al}-\mathrm{K} \alpha$ ) beam diameter of $100 \mu \mathrm{m}$ was applied for elemental analysis.

\section{Results and discussion}

The influence of surfactant addition on Zn-deposition/stripping was studied by cyclic voltammetry measurement with a sweep rate of $1 \mathrm{mV} \mathrm{s}^{-1}$ (Figure 2). In this work, the concentration of surfactant is extremely low $(1 \mathrm{mM})$, and it is thought that $\mathrm{Zn}^{2+}$ is still stabilized as a complex of $\left[\mathrm{Zn}(\mathrm{OH})_{4}\right]^{2-}$. Regardless of the type of surfactant, obvious reduction and oxidation peaks corresponding to $\mathrm{Zn}$ deposition and dissolution were confirmed, which indicates that the surfactants do not prevent charge transfer reactions. The electrodeposition reactions proceeded below $0 \mathrm{~V}$ vs. $\mathrm{Zn} / \mathrm{Zn}^{2+}$ as well as that in an additive free electrolyte $(0.25 \mathrm{M} \mathrm{ZnO}+4 \mathrm{M} \mathrm{KOH}$ aq. $)$. According to several literatures ${ }^{17,27,30}$, the second oxidation peak is derived from the formation of passivation film consisted of $\mathrm{ZnO}$. The solubility of $\left[\mathrm{Zn}(\mathrm{OH})_{4}\right]^{2-}$ is approximately $1 \mathrm{M}$ in $8 \mathrm{M}$ $\mathrm{KOH}$ aqueous solution. However, considering the dissolution process, the concentration of $\left[\mathrm{Zn}(\mathrm{OH})_{4}\right]^{2-}$ possibly exceeds saturated solubility in the vicinity of electrode surface and thereby results in its decomposition followed by $\mathrm{ZnO}$ precipitation. On the other hand, in the case of using organic and ionic-liquid electrolytes, ${ }^{24}$ only a peak can be observed, which also supports that the second oxidation peak is assigned to the formation of ZnO passivation film (Figure S1, Supporting 
Information). It is interesting that an oxidation (dissolution) peak position appeared at the lowest side when using STAC, which makes us expect that the charge/discharge hysteresis is small.

Figure 3 shows Zn electrodeposition behavior under constant current condition (10 mA $\mathrm{cm}^{-2}$ ) and XRD patterns of resulting deposits for charge amount of $10 \mathrm{~mA} \mathrm{~h} \mathrm{~cm}{ }^{-2}\left(36 \mathrm{C} \mathrm{cm}^{-2}\right)$. The XRD patterns were accordance with metallic Zn with hexagonal close-packed (hcp) crystal structure (ICSD: 00-004-0831), with small quantity of $\mathrm{Zn}(\mathrm{OH})_{2}$ and $\mathrm{ZnO}$ detected only by XPS spectra of Zn 2p and O 1s regions (Figure S2, Supporting Information). Additive free electrolyte allowed electrodeposition $\left(\mathrm{Zn}^{2+}+2 \mathrm{e}^{-} \rightarrow \mathrm{Zn}\right)$ at the potential of $-50 \mathrm{mV}$ vs. $\mathrm{Zn} / \mathrm{Zn}^{2+}$. The potential remained until $2 \mathrm{~mA} \mathrm{~h} \mathrm{~cm}{ }^{-2}$, and then continued to be flat at around $-40 \mathrm{mV}$. The slight potential rise to positive is thought to be induced by increase in reaction site, that is, the formation of mossy structure with high surface area. In fact, mossy structure was clearly observed from FE-SEM images of Zn deposits (Figure 4). It was reported that Zn morphologies depend on an overpotential during electrodeposition reaction; Otani and Homma et al. monitored deposition behavior by insitu optical microscopy and clarified that the formation and propagation of mossy structure successively continued at a low current density of $5.0 \mathrm{~mA} \mathrm{~cm}{ }^{-2} \cdot{ }^{16}$ In the proposed model of “terrace-kink-step"36, metal atoms firstly adsorb on a wide terrace with high surface area in a substrate and then to be adatoms. The adatoms diffuse and are incorporated to be stabilized. In the process, the case which adsorption rate exceeds surface diffusion rate makes nucleation easily occur on the terrace to form fine crystals with a large number. The filamentous fine crystals are responsible for non-uniform deposition morphology such as sponge and dendritic growth. In the opposite case, adatoms are incorporated at step edges and existing crystalline nucleus grows (lateral growth), in which deposition morphology becomes uniform. (0001) plane in Zn with hexagonal structure has wide terrace and diffusion of adatoms on the surface is lower compared to 
other planes. ${ }^{15,18,35}$ Therefore, the non-uniform electrodeposition tends to take place on (0001) plane. Indeed, in the additive free electrolyte, such unfavorable phenomenon was progressed regardless of current density: under a current density of $20 \mathrm{~mA} \mathrm{~cm}{ }^{-2}$, $\mathrm{Zn}$ was deposited accompanied with a large overpotential and resulted in texture where smooth region and mossy were mixed (Figures S3 and S4, Supporting Information). In the diffusion-controlled condition of $40 \mathrm{~mA} \mathrm{~cm}{ }^{-2}$, a leaf-like $\mathrm{Zn}$ dendrite which causes internal short circuits was formed. The use of SDS and PAA have little influence on the improvement of deposition morphology, and the unfavorable shape change was not avoided: while SDS delivered a sponge-like Zn deposition as it was for additive free electrolyte, PAA resulted in interconnected granules even in the same mossy form. On the other hand, in the presence of STAC, Zn deposition morphology was dramatically improved to be smooth, with no protrusion and filament causing sponge-like growth observed. The degree of smooth is shown prominently from CLSM images and cross-sectional FE-SEM images obtained in each electrolyte (Figures S5 and S6, Supporting Information). In the present experimental condition, a charge capacity corresponds to $17 \mu \mathrm{m}$ thickness of $\mathrm{Zn}$ deposit. It is noteworthy that the obtained thickness was good agreement with the theoretical one, which demonstrates that STAC surfactant with cationic charge acts as a leveling agent. In contrast, Zn deposits in other systems grew to a maximum of $200 \mu \mathrm{m}$. The root-mean-square roughness of the Zn deposits (RMS), an index parameter of the degree of irregularity was analyzed by CLSM also showed that there was a height difference of $100 \mu \mathrm{m}$ or more in the electrolyte solutions of additive free, $1 \mathrm{mM}$ SDS, and $1 \mathrm{mM}$ PAA.

To understand textural change during the above electrochemical growth, we investigated the crystal orientation of the $\mathrm{Zn}$ deposits at each charge capacity by the calculation of relative texture coefficient $\mathrm{RTC}_{(\mathrm{hkl})}$ according to the following equation: ${ }^{37,38}$ 


$$
\mathrm{RTC}_{(h k l)}=\frac{I_{h k l} / I_{h k l}^{o}}{\sum_{1}^{5} I_{h k l} / I_{h k l}^{o}} \times 100 \%
$$

where $I_{\mathrm{hkl}}$ and $I^{\mathrm{o}}{ }_{\mathrm{hkl}}$ denote the diffraction intensities of the $(h k l)$ lines for the deposited $\mathrm{Zn}$ and the corresponding intensities of the standard Zn powder sample which is randomly orientated, respectively. Since we focused on five dominant peaks of Zn (002), (100), (101), (102), and (110) planes, a preferred orientation through an axis [hkl] is indicated by values of $R T C \geq 20 \%$, and the preferred orientation is absolute when $R T C$ approaches the value of $100 \%$. Figure 5a shows relative texture coefficient with a charge capacity in electrolytes with and without 1 mM STAC. Regardless of the presence or absence of additive, [101] and [102] were preferred orientation in the early stage of $\mathrm{Zn}$ electrodeposition $\left(1 \mathrm{~mA} \mathrm{~h} \mathrm{~cm}^{-2}\right)$. In the additive free electrolyte, the tendency had little change even at the capacities of 5 and $10 \mathrm{~mA} \mathrm{~h} \mathrm{~cm}^{-2}$. On the other hand, in an electrolyte containing $1 \mathrm{mM}$ STAC, the orientation to [110] became more pronounced along with an electrochemical $\mathrm{Zn}$ growth, whereas the growth of direction to [101] and [102] was gradually suppressed. The leveling effect by the addition of STAC was significantly remarkable at a concentration of $10 \mathrm{mM}$ : the relative texture coefficient for [110] orientation resulted in 96\% (Figures S7, S8, and S9 Supporting Information), which means that fine structure of $\mathrm{Zn}$ formed by electrodeposition is controllable by using cationic surfactant STAC. With increasing concentration of STAC from 0.1 to $10 \mathrm{mM}$, an overpotential during electrodeposition became significant and Zn particle size gradually decreased. In the case of using $0.1 \mathrm{mM}$ of STAC, spherical deposits were also observed and partially smoothed Zn was achieved. At a concentration of $1 \mathrm{mM}$ or more, leveling effect was clearly shown. In addition, it should be noted that protrusions observed in an electrolyte with a low concentration of $0.1 \mathrm{mM}$ STAC cannot be recognized. Compared with Tafel plots obtained by 
measuring an overpotential during Zn deposition vs. various applied current densities (Figure 5b), an additive free electrolyte delivered higher kinetic current density $\left(2.06 \mathrm{~mA} \mathrm{~cm}^{-2}\right)$ than that $1 \mathrm{mM}$ STAC-containing electrolyte $\left(1.40 \mathrm{~mA} \mathrm{~cm}{ }^{-2}\right)$. In this work, we defined $\eta$ as the refence electrode potential in an alkaline aqueous solution. This phenomenon implies that dissociated trimethyloctadecylammonium cations (STAC) exist at the electrode-electrolyte interface and has influence on the electrochemical reduction of $\mathrm{Zn}^{2+}$. In an additive free electrolyte, once protrusions are formed, the current density distribution is inhomogeneous to concentrate pertly, which causes a mossy structure and dendritic growth in low and high current density, respectively. We hypothesized the smoothing effect of Zn deposition in the presence of STAC as follows: if protrusions were formed, dissociated ammonium cations (STAC) with bulky size adsorb to the regions which a strong electric field is applied and suppress the electrodeposition reaction. Then lateral growth is promoted compared to that in the absence of the additive. We therefore evaluated whether dissociated ion has a positive or negative charge.

Figure 6a compares ionicity of dissociated ion of surfactants used in the present study by $\zeta$ potential measurements according to Smoluchowski equation: ${ }^{39,40}$

$$
\mu=\frac{\varepsilon_{0} \varepsilon_{\mathrm{r}} \zeta}{\eta}
$$

where the symbols $\mu, \varepsilon_{0}, \varepsilon_{\mathrm{r}}$, and $\eta$ stand for electrophoretic mobility, relative dielectric constant of water, and dielectric constant of vacuum, and viscosity of solution, respectively. In the present study, we approximate Stern potential $\left(\phi_{\delta}\right)$ by zeta potential $(\zeta)$. Originally, Stern potential comes from adsorption layer (Stern layer), central plane in which active counter ions are closest. ${ }^{41}$ PTFE particles were dispersed in alkaline solution with respective additives (SDS, PAA, and STAC) 
with $1 \mathrm{mM}$ concentration and the $\zeta$ potential depending on dissociated ion adsorbed on the particles were used as an indicator of ionicity. In an additive free solution, PTFE was charged negatively $(-47.8 \mathrm{mV})$. In SDS-containing electrolyte, $\zeta$ potential value showed $-56.6 \mathrm{mV}$, which means a moiety of dissociated SDS is anionic and adsorbs on the particle. Although we chose PAA as a non-ionic surfactant, PAA ionized to behave like an anion $(-69.3 \mathrm{mV})$. Dissociated STAC, a quaternary ammonium cation with long alkyl chain length $\left(\mathrm{C}_{18}\right)$, exhibited only positive value of $+34.8 \mathrm{mV}$. Based on the results, the smooth Zn growth when using STAC surfactant is probably because bulky ammonium cations adsorb on the protrusions generated at both low and high current densities by the electrostatic interaction, and the adsorption suppresses electrochemical depositions in the region and promotes lateral growth (Figure 6b). In electrolytes with $1 \mathrm{mM}$ SDS or PAA, it is clear that there is no significant difference in not only orientation for both Zn deposits in $\mathrm{RTC}_{(h k l)}$ but also deposition morphologies, compared with that obtained from an additive free electrolyte (Figure S10 Supporting Information). The electrostatic interaction between the quaternary ammonium ion and $\mathrm{Zn}$ electrode is also supported by electrochemical impedance spectroscopic analysis (Figure S11Supporting Information). SDS with a negative charge did not involve in charge transfer reaction associated with Zn-deposition/dissolution and the resistance value depending the size of a semicircle is same degree in comparison with that in an additive free electrolyte. Although PAA had an influence on charge transfer, the resistance was far smaller than that in 1 mM-SATC containing electrolyte. Anionic surfactants without an electrostatic interaction in the present study did not contribute to smoothing effect. In other words, we consider that only cationic surfactant plays a key role of leveling for Zn deposit. The adsorption of dissociated ion is presumably responsible for the overpotential and the lower kinetic current density, as shown in Figures $3 a$ and $5 b$. 
The influence of an applied potential was also studied by a chronoamperometry. The potential of $-90 \mathrm{mV}$ vs. $\mathrm{Zn} / \mathrm{Zn}^{2+}$, the steady potential observed under constant current density of $10 \mathrm{~mA} \mathrm{~cm}^{-2}$ in $1 \mathrm{mM}$ STAC-containing electrolyte, was applied and time dependence of current density for Zn electrodeposition was recorded (Figure 7a). From the initial stage to Zn electrodeposition capacity of $10 \mathrm{~mA} \mathrm{~h} \mathrm{~cm}{ }^{-2}$, the current density in the additive free electrolyte was gradually increased with time. After electrodeposition, the deposits resulted in mixed surface morphology consisted of smooth and mossy structures (Figure 7b). In contrast, the current density in case of adding of $1 \mathrm{mM}$ STAC remained at around $-10 \mathrm{~mA} \mathrm{~cm}^{-2}$ and smooth $\mathrm{Zn}$ deposits were obtained, which suggests that the leveling effect is not originated simply from the overpotential, but from the adsorption of surfactant. The favorable effect was recognized in wide current densities from 5 to $20 \mathrm{~mA} \mathrm{~cm}^{-2}$. In even the high rate of $20 \mathrm{~mA} \mathrm{~cm}^{-2}$, flat morphology was obtained (Figures S12 and S13, Supporting Information). The size of Zn particle generated by electrodeposition became larger with increasing current density. Dendritic growth typically observed at high current density was mitigated at $40 \mathrm{~mA} \mathrm{~cm}{ }^{-2}$ in $1 \mathrm{mM} \mathrm{STAC-containing} \mathrm{electrolyte} \mathrm{though} \mathrm{asperity} \mathrm{was}$ easy to notice. In the high current density, potential oscillation which is closely related to diffusionlimited condition was visible in electrodeposition behavior. ${ }^{10,22}$

Figure 8 represents cycling performance of symmetric cells consisted of Zn metal sheets under constant current density of $10 \mathrm{~mA} \mathrm{~cm}^{-2}$ for long term of $200 \mathrm{~h}$, which clearly showed the advantage of using STAC surfactant. An average overvoltage between Zn-deposition/stripping in an additive free electrolyte was about $100 \mathrm{mV}$ at the initial stage and the hysteresis gradually increased to $180 \mathrm{mV}$ after $20 \mathrm{~h}$. Then, the overvoltage suddenly increased at $156 \mathrm{~h}$, which is possibly caused by the passivation by accumulation of insulator $\mathrm{ZnO}$ and $\mathrm{Zn}(\mathrm{OH})_{2}$ formed on $\mathrm{Zn}$ surface. Although SDS and PAA delivered smaller hysteresis than those in an additive free 
electrolyte and an electrolyte with $1 \mathrm{mM}$ STAC at an earlier stage, the behavior with SDS and PAA was unstable: the voltage for electrodeposition/dissolution suddenly became small or large. The drastically small overvoltage is probably due to their large surface area originated from mossy structure as shown in Figure 4. It is considered that the formation of passivation layer such as $\mathrm{ZnO}$ should be responsible for the sudden change in the overvoltage. Such unstable behavior was repeatedly confirmed, which also supports inhomogeneous Zn-deposition/dissolution reactions (Figure S14 and S15, Supporting Information). Contrary to the profiles observed in the electrolyte, the overvoltage in an electrolyte with $1 \mathrm{mM}$ STAC showed stable $(<120 \mathrm{mV})$ and the voltage fluctuation was negligible though the overvoltage was larger than that in the additive free electrolyte at the beginning ( $\sim 20 \mathrm{~h}$ ). The more stable and lower polarization is due to the smaller shape change in Zn metal sheet, as shown in the inset photographs. The inhibition effect of mossy and dendritic growth is also demonstrated in $\mathrm{Cu} \mid \mathrm{Zn}$ asymmetric cells (Figure 9). The $\mathrm{Zn}$ deposition potentials in $1 \mathrm{mM}$-STAC containing electrolyte were continued to be lower than those of the electrolyte without any additive, demonstrating that the effect of surfactant addition was successfully sustained during 300th cycle (Figure 9a). As for the additive free system, the reversibility of Zn-deposition/striping remained at a low level below 95\%. The discharge capacity loss is associated with dead $\mathrm{Zn}$, i.e., an electrical isolation of $\mathrm{Zn}$ deposit from a $\mathrm{Cu}$ substrate in the middle of dissolution reaction. In fact, deposited Zn underwent a significant morphology change after 300th cycle (Figure S15, Supporting Information). No decrease in Coulombic efficiency was observed and superior cycling performance was achieved by the addition of STAC. The results indicate that the addition of surfactant to electrolyte solution is a promising way to control $\mathrm{Zn}$ deposition morphology. We are currently investigating the size of dissociated cation and alkyl 
chain length for the purpose of controlling the deposition morphology in a wide range of current density.

\section{Conclusions}

Zn-deposition morphology and deposition/stripping properties in the presence of surfactant were studied in view of the electric charge using cyclic voltammetry and charge-discharge tests. In an additive free electrolyte and with $1 \mathrm{mM}$ SDS and PAA under a current density of $10 \mathrm{~mA}$ $\mathrm{cm}^{-2}, \mathrm{Zn}$ electrochemically grew in the form of mossy with a thickness of $100 \mu \mathrm{m}$ or more, whereas the addition of $1 \mathrm{mM}$ STAC resulted in the formation of significantly smooth and dense structure in accordance with the theoretical thickness of $17 \mu \mathrm{m}$. In that case, the orientation to [110] became more pronounced along with deposition capacity. $\zeta$ potential measurements and kinetic current densities obtained from Tafel plots indicated that trimethyloctadecylammonium cations (dissociated STAC) adsorb on protrusions to suppress shape change and promote lateral growth. A symmetric cell of $\mathrm{Zn} \mid \mathrm{Zn}$ in $1 \mathrm{mM}$-containing electrolyte allowed stable overvoltage behavior during long-term 1000th cycle (200 h). In a charge-discharge test, a high reversibility of Zndeposition/stripping was maintained without any capacity loss even after 300th cycle.

\section{Conflicts of interest}

There are no conflicts to declare.

\section{Acknowledgments}


This work was supported by Early-Career Scientists (18K14317) and Grant-in-Aid for Research Activity Start-up (16H06838) from the Japan Society for the Promotion of Science (JSPS) and a research grant from the Iketani Science and Technology Foundation (0301043-A). M. Shimizu gratefully acknowledge T. Elliot for her heartfelt advice. The authors thank Nagano Technical High-School students (E. Furusawa, T. Yamazaki, S. Tokida, and T. Ito) for their kind assistance.

\section{Notes and references}

1 J. Muldoon, C. B. Bucur and T. Gregory, Chem. Rev., 2014, 114, 11683-11720.

2 A. C. Luntz and B. D. McCloskey, Chem. Rev., 2014, 114, 11721-11750.

3 Y. Li and H. Dai, Chem. Soc. Rev., 2014, 43, 5257-5275.

4 M. Xu, D. G. Ivey, Z. Xie and W. Qu, J. Power Sources, 2015, 283, 358-371.

5 A. L. Zhu, D. P. Wilkinson, X. Zhang, Y. Xing, A. G. Rozhin and S. A. Kulinich, J. Energy Storage, 2016, 8, 35-50.

6 J. Fu, Z. P. Cano, M. G. Park, A. Yu, M. Fowler and Z. Chen, Adv Mater., 2017, 29, 1604685.

7 F. Wang, O. Borodin, T. Gao, X. Fan, W. Sun, F. Han, A. Faraone, J. A. Dura, K. Xu and C. Wang, Nat. Mater., 2018, 17, 543-549.

8 S.-J. Kim, H.-T. Kim and S.-M. Park, J. Electrochem. Soc., 2004, 151, C850-C854.

9 A. Koyama, K. Fukami, Y. Suzuki, A. Kitada, T. Sakka, T. Abe, K. Murase and M. Kinoshita, J. Phys. Chem. C, 2016, 120, 24112-24120.

10 K. Fukami, S. Nakanishi, T. Tada, H. Yamasaki, S.-I. Sakai, S. Fukushima and Y. Nakato, J. Electrochem. Soc., 2005, 152, C493-C497.

11 C. Xu, B. Li, H. Du and F. Kang, Angew. Chem., 2012, 51, 933-935.

12 L. Wei, H. E. Karahan, S. Zhai, H. Liu, X. Chen, Z. Zhou, Y. Lei, Z. Liu and Y. Chen, Adv Mater., 2017, 29, 1701410.

13 E. Tsuji, T. Motohashi, H. Noda, D. Kowalski, Y. Aoki, H. Tanida, J. Niikura, Y. Koyama, M. Mori, H. Arai, T. Ioroi, N. Fujiwara, Y. Uchimoto, Z. Ogumi and H. Habazaki, ChemSusChem, 2017, 10, 2864-2868.

14 Y. Li, M. Gong, Y. Liang, J. Feng, J. E. Kim, H. Wang, G. Hong, B. Zhang and H. Dai, Nat. Commun., 2013, 4, 1805. 
15 T. Mitsuhashi, Y. Ito, Y. Takeuchi, S. Harada and T. Ujihara, Thin Solid Films, 2015, 590, 207-213.

16 T. Otani, M. Nagata, Y. Fukunaka and T. Homma, Electrochim. Acta, 2016, 206, 366-373.

17 M. Azhagurajan, A. Nakata, H. Arai, Z. Ogumi, T. Kajita, T. Ito and K. Itaya, J. Electrochem. Soc., 2017, 164, A2407-A2417.

18 T. K. A. Hoang, M. Acton, H. T. H. Chen, Y. Huang, T. N. L. Doan and P. Chen, Mater. Today Energy, 2017, 4, 34-40.

19 T. Otani, Y. Fukunaka and T. Homma, Electrochim. Acta, 2017, 242, 364-372.

20 K. E. Sun, T. K. Hoang, T. N. Doan, Y. Yu, X. Zhu, Y. Tian and P. Chen, ACS Appl. Mater. Interfaces, 2017, 9, 9681-9687.

21 J. H. Park, N. M. Schneider, D. A. Steingart, H. Deligianni, S. Kodambaka and F. M. Ross, Nano Lett., 2018, 18, 1093-1098.

22 K. Miyazaki, A. Nakata, Y.-S. Lee, T. Fukutsuka and T. Abe, J. Appl. Electrochem., 2016, 46, $1067-1073$.

23 T. J. Simons, A. A. J. Torriero, P. C. Howlett, D. R. MacFarlane and M. Forsyth, Electrochem. Commun., 2012, 18, 119-122.

24 S. D. Han, N. N. Rajput, X. Qu, B. Pan, M. He, M. S. Ferrandon, C. Liao, K. A. Persson and A. K. Burrell, ACS Appl. Mater. Interfaces, 2016, 8, 3021-3031.

25 Z. Liu, T. Cui, G. Pulletikurthi, A. Lahiri, T. Carstens, M. Olschewski and F. Endres, Angew. Chem., 2016, 55, 2889-2893.

26 Z. Liu, G. Pulletikurthi, A. Lahiri, T. Cui and F. Endres, Dalton Trans., 2016, 45, 8089-8098.

27 A. Nakata, H. Arai, T. Yamane, T. Hirai and Z. Ogumi, J. Electrochem. Soc., 2016, 163, A50-A56.

28 Y.-H. Chen, H.-W. Yeh, N.-C. Lo, C.-W. Chiu, I. W. Sun and P.-Y. Chen, Electrochim. Acta, 2017, 227, 185-193.

29 X. Wei, D. Desai, G. G. Yadav, D. E. Turney, A. Couzis and S. Banerjee, Electrochim. Acta, 2016, 212, 603-613.

30 D. Stock, S. Dongmo, F. Walther, J. Sann, J. Janek and D. Schroder, ACS Appl. Mater. Interfaces, 2018, 10, 8640-8648.

31 K. Miyazaki, Y. S. Lee, T. Fukutsuka and T. Abe, Electrochemistry, 2012, 80, 725-727. 
32 J. F. Parker, E. S. Nelson, M. D. Wattendorf, C. N. Chervin, J. W. Long and D. R. Rolison, ACS Appl. Mater. Interfaces, 2014, 6, 19471-19476.

33 L.-P. Wang, N.-W. Li, T.-S. Wang, Y.-X. Yin, Y.-G. Guo and C.-R. Wang, Electrochim. Acta, 2017, 244, 172-177.

34 S. Higashi, S. W. Lee, J. S. Lee, K. Takechi and Y. Cui, Nat. Commun., 2016, 7, 11801.

35 K. Fukami, S. Nakanishi, S.-i. Sakai and Y. Nakato, Chem. Lett., 2003, 32, 532-533.

36 F. K. Crundwell, Cryst. Growth Des., 2016, 16, 5877-5886.

37 M. Shimizu, R. Yatsuzuka, M. Horita, T. Yamamoto and S. Arai, J. Phys. Chem. C, 2017, 121, 27285-27294.

38 E. A. Pavlatou, M. Raptakis and N. Spyrellis, Surf. Coat. Technol., 2007, 201, 4571-4577.

39 S. Arai and T. Osaki, J. Electrochem. Soc., 2014, 162, D68-D73.

40 M. Khademi, W. Wang, W. Reitinger and D. P. J. Barz, Langmuir, 2017, 33, 10473-10482.

41 R. Scheu, Y. Chen, M. Subinya and S. Roke, J. Am. Chem. Soc., 2013, 135, 19330-19335. 


\section{Figure captions}

Figure 1. Chemical structures of various surfactants and schematic diagram of a three-electrode type electrochemical cell used in the present study. Zn-deposition area was set to approximately $1.7 \mathrm{~cm}^{2}(\Phi 15 \mathrm{~mm})$.

Figure 2. Cyclic voltammograms corresponding to Zn-deposition/stripping in aqueous solutions of $0.25 \mathrm{M}+4 \mathrm{M} \mathrm{KOH}$ without and with surfactant (SDS, PAA, and STAC). The area of current collector was $1.7 \mathrm{~cm}^{2}$.

Figure 3. Charge (Zn deposition) behaviors and photographs of the resulting deposits in electrolyte solutions (0.25 M ZnO + $4 \mathrm{M} \mathrm{KOH}$ ) without and with $1 \mathrm{mM}$ surfactant (SDS, PAA, STAC). The overpotential against equilibrium potential $\left(\mathrm{Zn}^{2+}+2 \mathrm{e}^{-} \rightarrow \mathrm{Zn}\right)$ in the respective electrolyte was 40 $\mathrm{mV}$ (additive free), $47 \mathrm{mV}$ (SDS), $50 \mathrm{mV}$ (PAA), and $90 \mathrm{mV}$ (STAC).

Figure 4. Surface and cross-sectional (bottom) FE-SEM images of Zn deposits in zincate-based electrolytes without and with $1 \mathrm{mM}$ additive (SDS, PAA, and STAC). A focused ion beam was

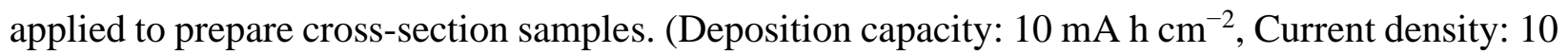
$\mathrm{mA} \mathrm{cm}{ }^{-2}$ )

Figure 5. (a) Change in the relative texture coefficient for Zn (110), (002), (100), (101), and (102) diffraction peaks as a function of charge capacity in an additive free electrolyte $(0.25 \mathrm{M} \mathrm{ZnO/4M}$ $\mathrm{KOH}$ ) and $1 \mathrm{mM}-\mathrm{STAC}$ containing electrolyte. As a reference, commercially available Zn powder that is randomly orientated was used. (b) Tafel plot for Zn electrodeposition at different current densities.

Figure 6. (a) Indicator for strength of electrical charge: Zeta potentials of PTFE particles (diameter: $200 \mathrm{~nm}$ ) granted by SDS, PAA, and STAC surfactants. For comparison, the potential in additive free electrolyte is also shown. (b) Proposed leveling mechanism of Zn deposition using STAC (cationic surfactant) under galvanostatic condition. 
Figure 7. (a) Time dependence of current density for Zn electrodeposition in the constant potential of $-90 \mathrm{mV}$ vs. $\mathrm{Zn} / \mathrm{Zn}^{2+}$. (b) Surface FE-SEM images of the deposited $\mathrm{Zn}$. The constant electrolysis was finished when the charge amount for the electrodeposition reached to $10 \mathrm{~mA} \mathrm{~h} \mathrm{~cm}{ }^{-2}$. Inset: photographs of deposits.

Figure 8. Long-term cycling of symmetric Zn|Zn cells operated under a current density of $10 \mathrm{~mA}$ $\mathrm{cm}^{-2}$. The charge/discharge capacities were set to $1 \mathrm{~mA} \mathrm{~h} \mathrm{~cm}{ }^{-2}$. Inset: photographs of $\mathrm{Zn}$ metal sheets after the Zn-deposition/stripping test.

Figure 9. (a) Charge-discharge profiles and (b) dependence of Coulombic efficiency on cycle number for Zn-deposition/stripping in additive free and 1 mM-STAC containing electrolyte. 
Graphical and textual abstract for the content page

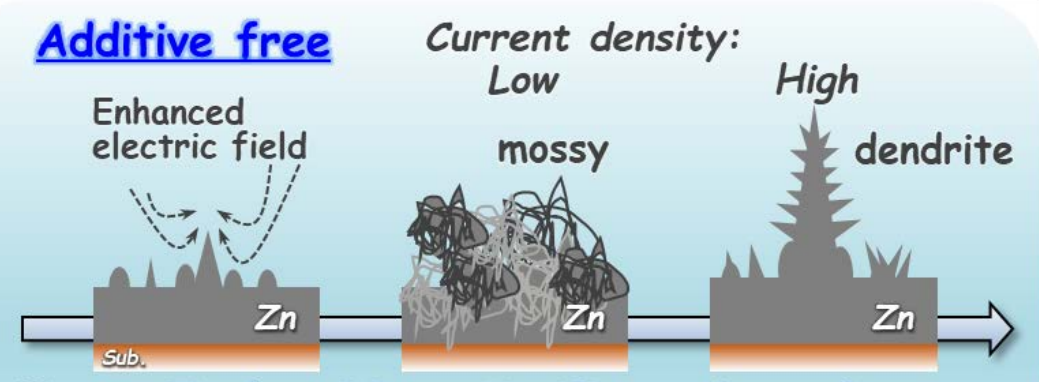

Uneven Zn deposition Significant shape change

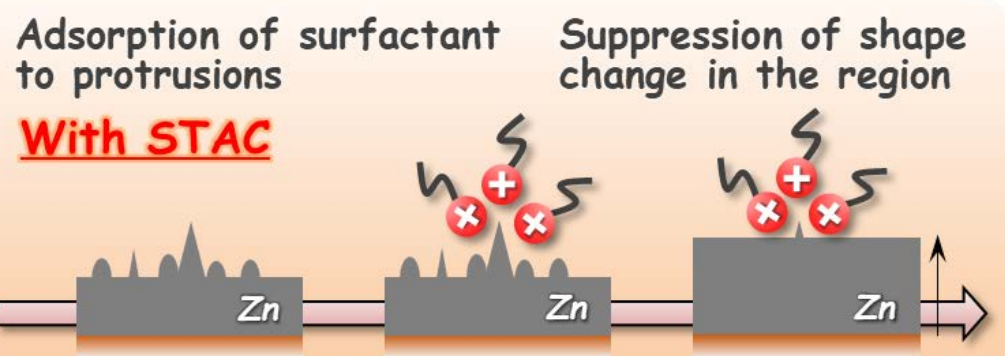

Smooth deposition in a wide current density range 
Chemical structure

SDS: anionic surfactant (sodium dodecyl sulfate)<smiles>CCCCCO[SH](O)(O)(O)O[NH3+]</smiles>

PAA: non-ionic surfactant (polyacrylic acid, $M_{\mathrm{w}}=5000$ )<smiles>CCC(C)C(=O)O</smiles>

STAC: cationic surfactant (trimethyloctadecylammonium chloride)<smiles>CCCCC[N+](C)(C)Cl</smiles>

\section{Electrochemical cell}

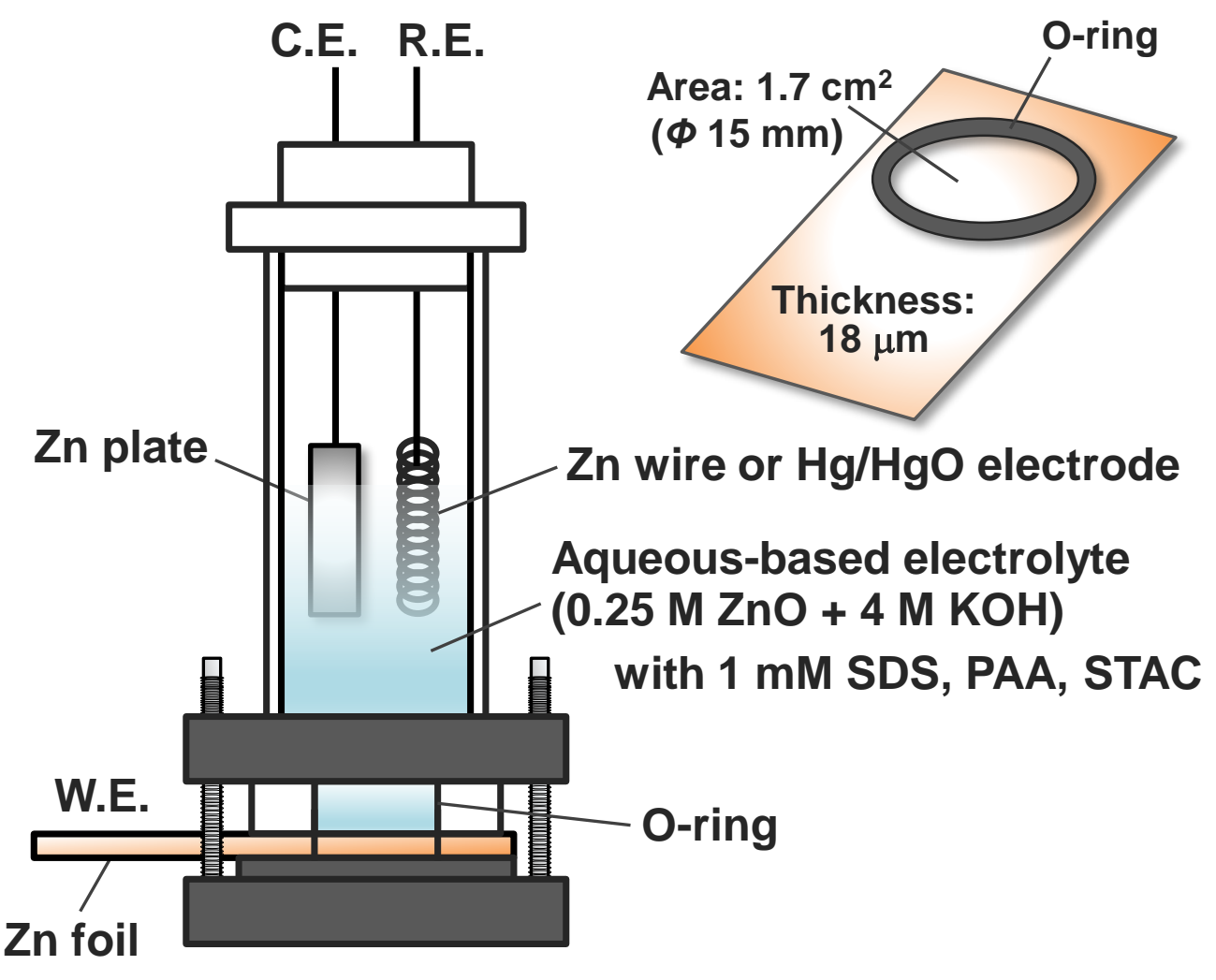

Figure 1. Chemical structures of various surfactants and schematic diagram of a three-electrode type electrochemical cell used in the present study. Zn-deposition area was set to approximately $1.7 \mathrm{~cm}^{2}(\Phi 15 \mathrm{~mm})$. 

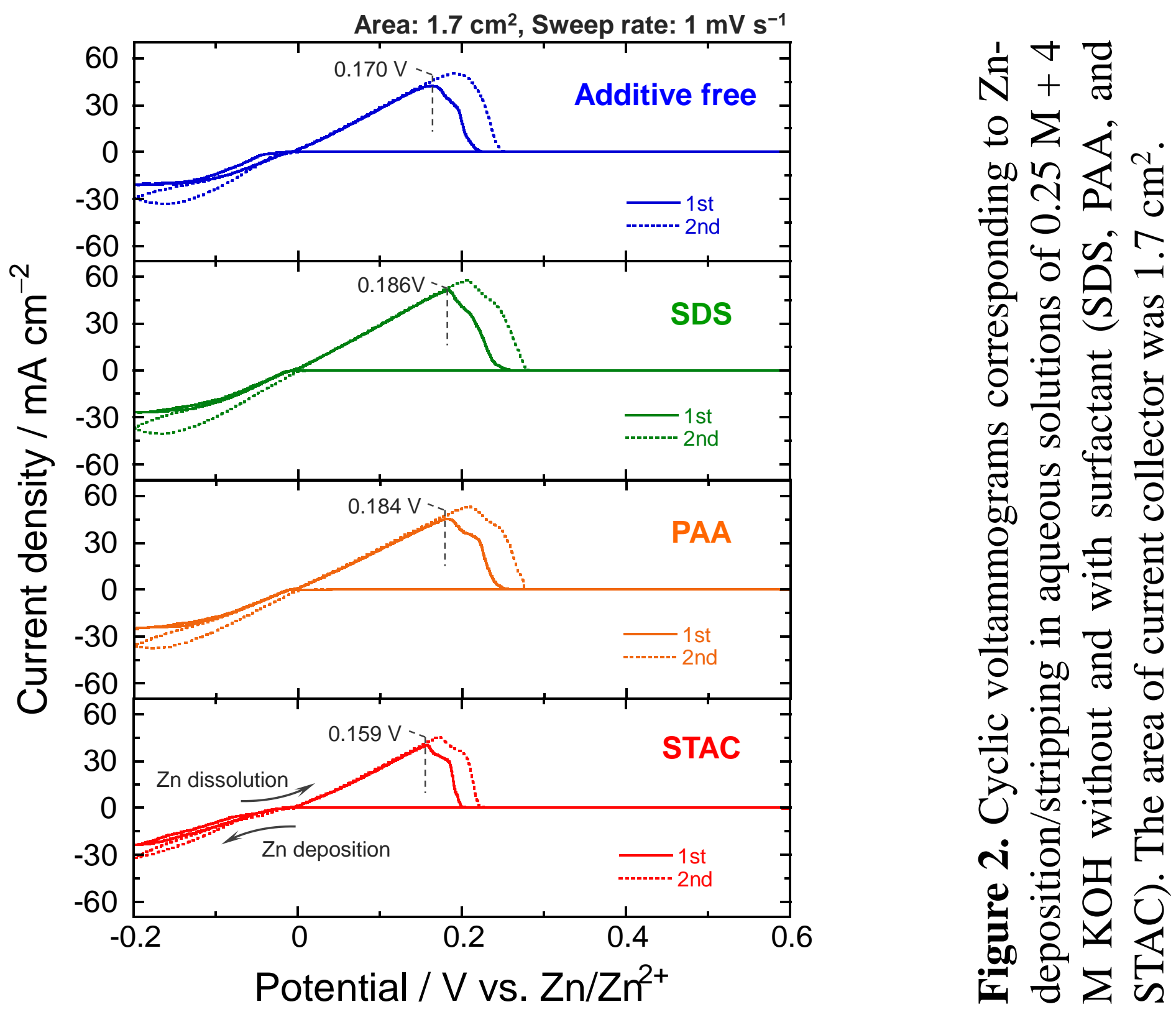

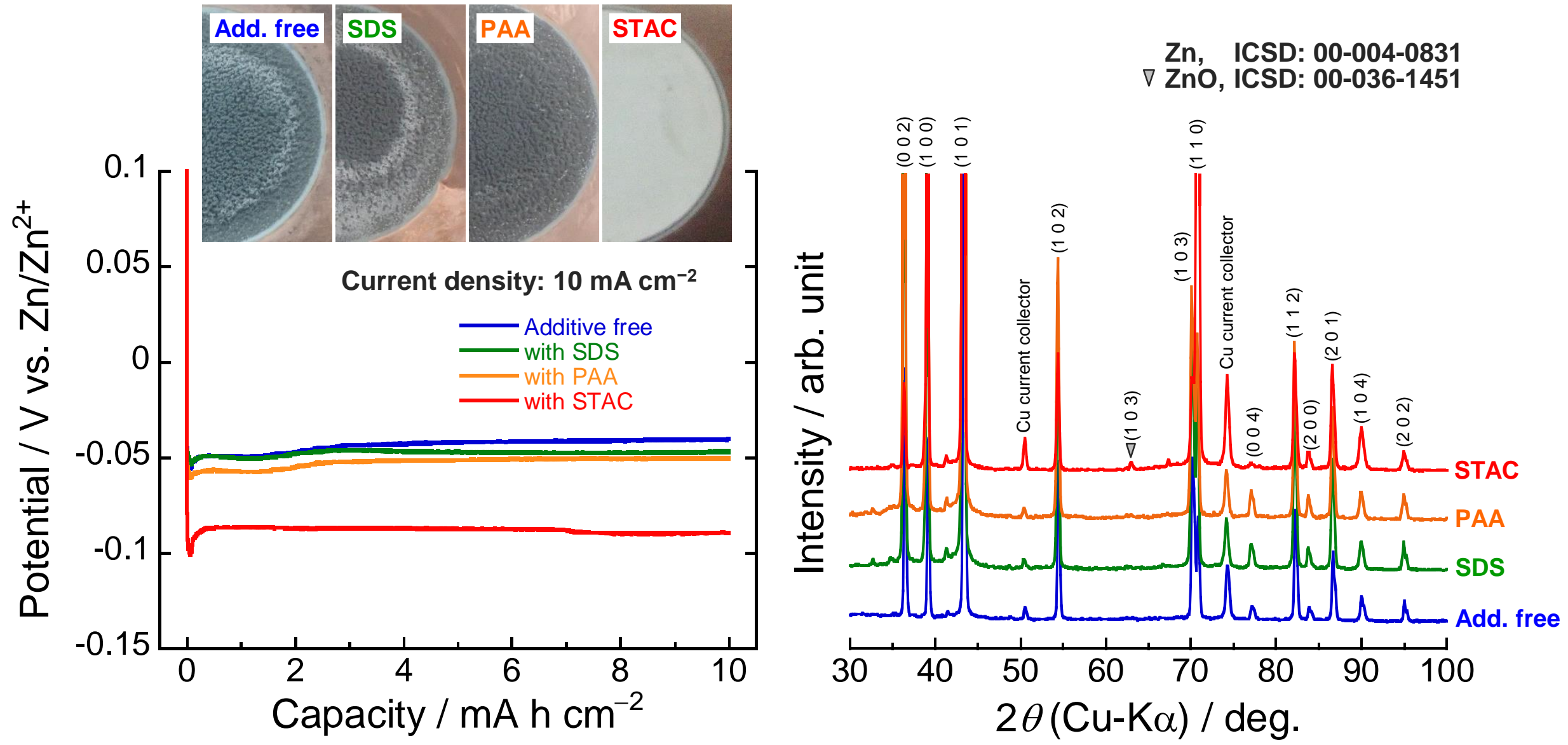

Figure 3. Charge ( $\mathrm{Zn}$ deposition) behaviors and photographs of the resulting deposits in electrolyte solutions $(0.25 \mathrm{M} \mathrm{ZnO}+4 \mathrm{M} \mathrm{KOH})$ without and with 1 $\mathrm{mM}$ surfactant (SDS, PAA, STAC). The overpotential against equilibrium potential $\left(\mathrm{Zn}^{2+}+2 \mathrm{e}^{-} \rightarrow \mathrm{Zn}\right)$ in the respective electrolyte was $40 \mathrm{mV}$ (additive free), $47 \mathrm{mV}$ (SDS), $50 \mathrm{mV}$ (PAA), and $90 \mathrm{mV}$ (STAC). 


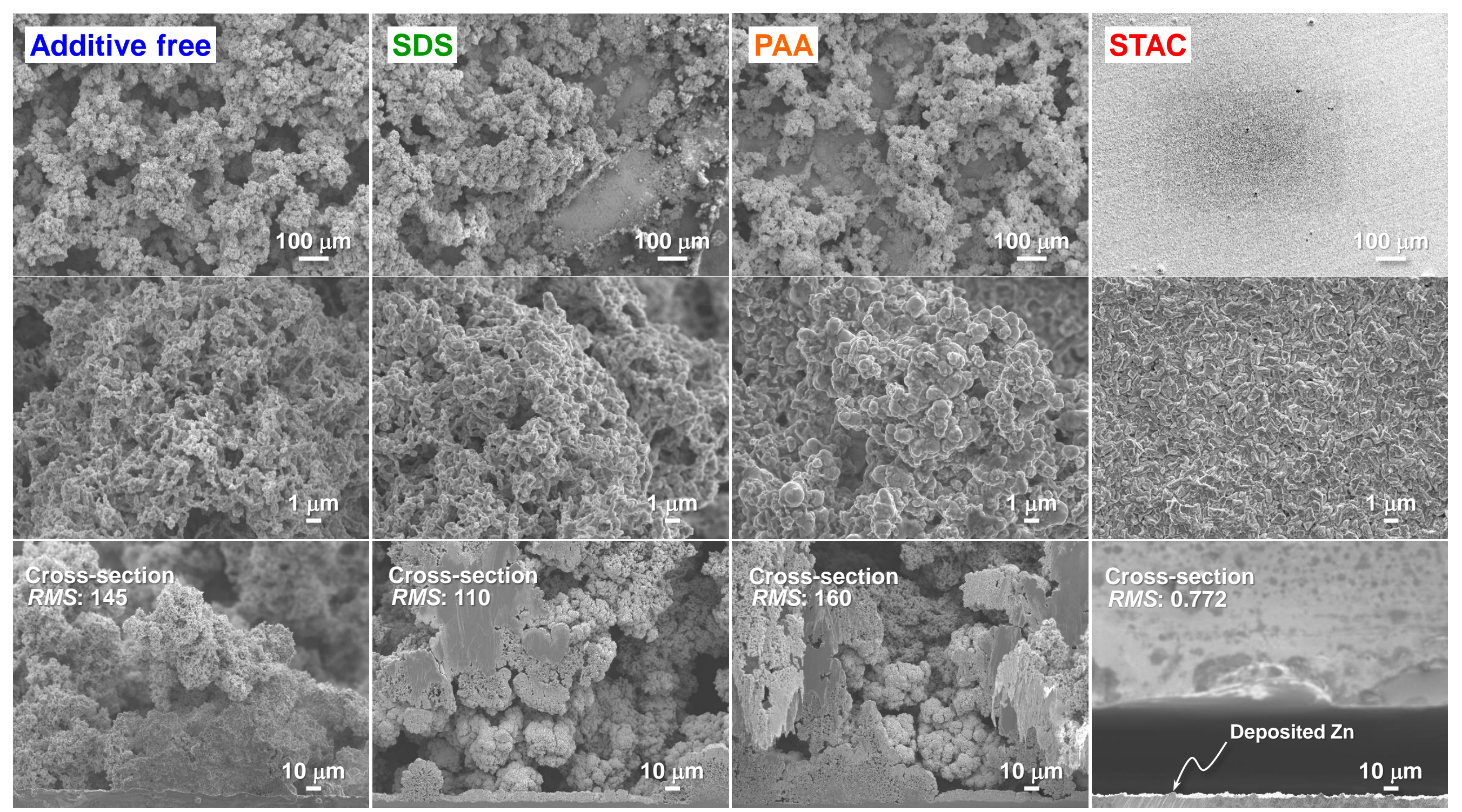

Figure 4. Surface and cross-sectional (bottom) FE-SEM images of Zn deposits in zincate-based electrolytes without and with $1 \mathrm{mM}$ additive (SDS, PAA, and STAC). A focused ion beam was applied to prepare cross-section samples. (Deposition capacity: $10 \mathrm{~mA} \mathrm{~h} \mathrm{~cm}{ }^{-2}$, Current density: $10 \mathrm{~mA} \mathrm{~cm}^{-2}$ ) 

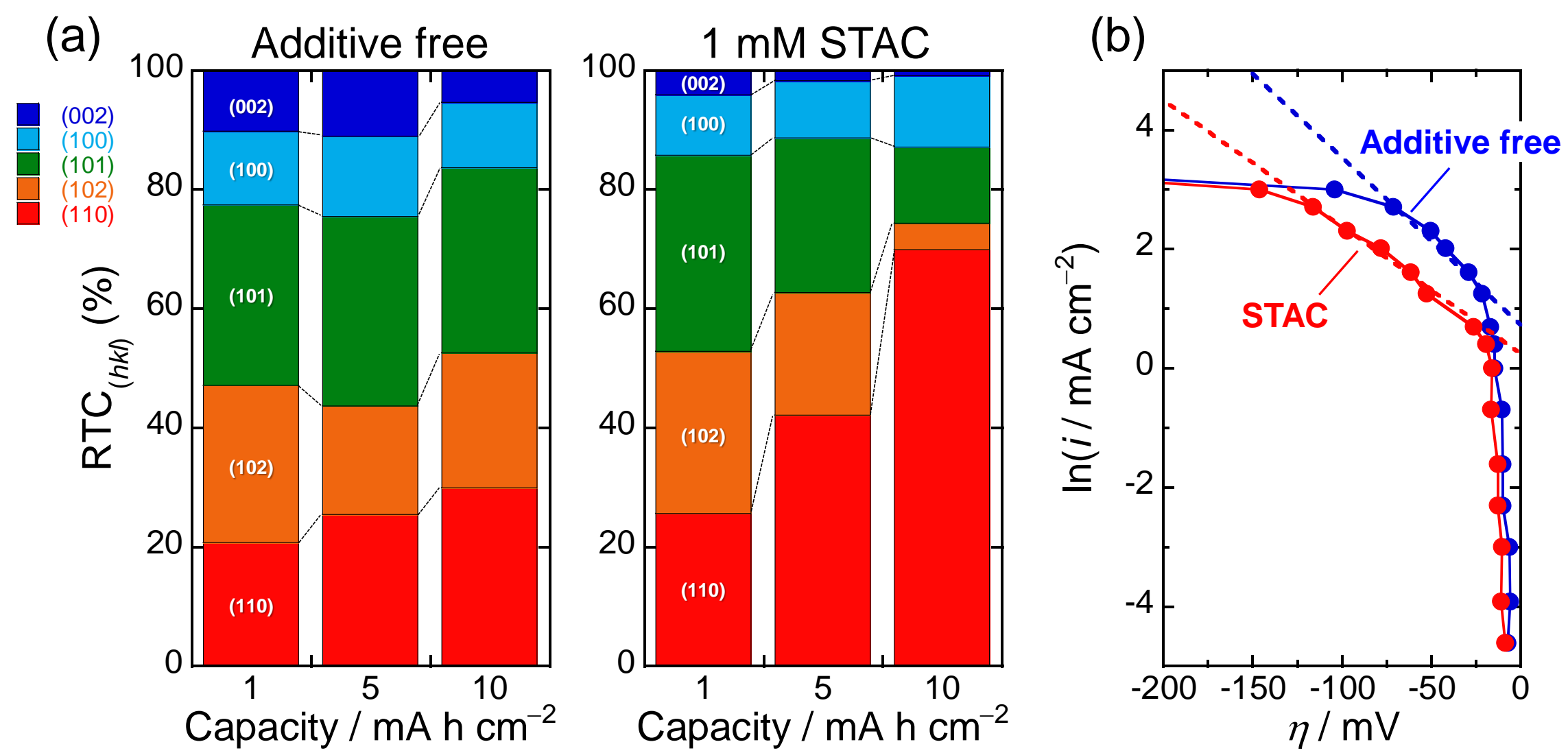

Figure 5. (a) Change in the relative texture coefficient for $\mathrm{Zn}$ (110), (002), (100), (101), and (102) diffraction peaks as a function of charge capacity in an additive free electrolyte $(0.25 \mathrm{M} \mathrm{ZnO} / 4 \mathrm{M} \mathrm{KOH})$ and $1 \mathrm{mM}-\mathrm{STAC}$ containing electrolyte. As a reference, commercially available $\mathrm{Zn}$ powder that is randomly orientated was used. (b) Tafel plot for $\mathrm{Zn}$ electrodeposition at different current densities. 

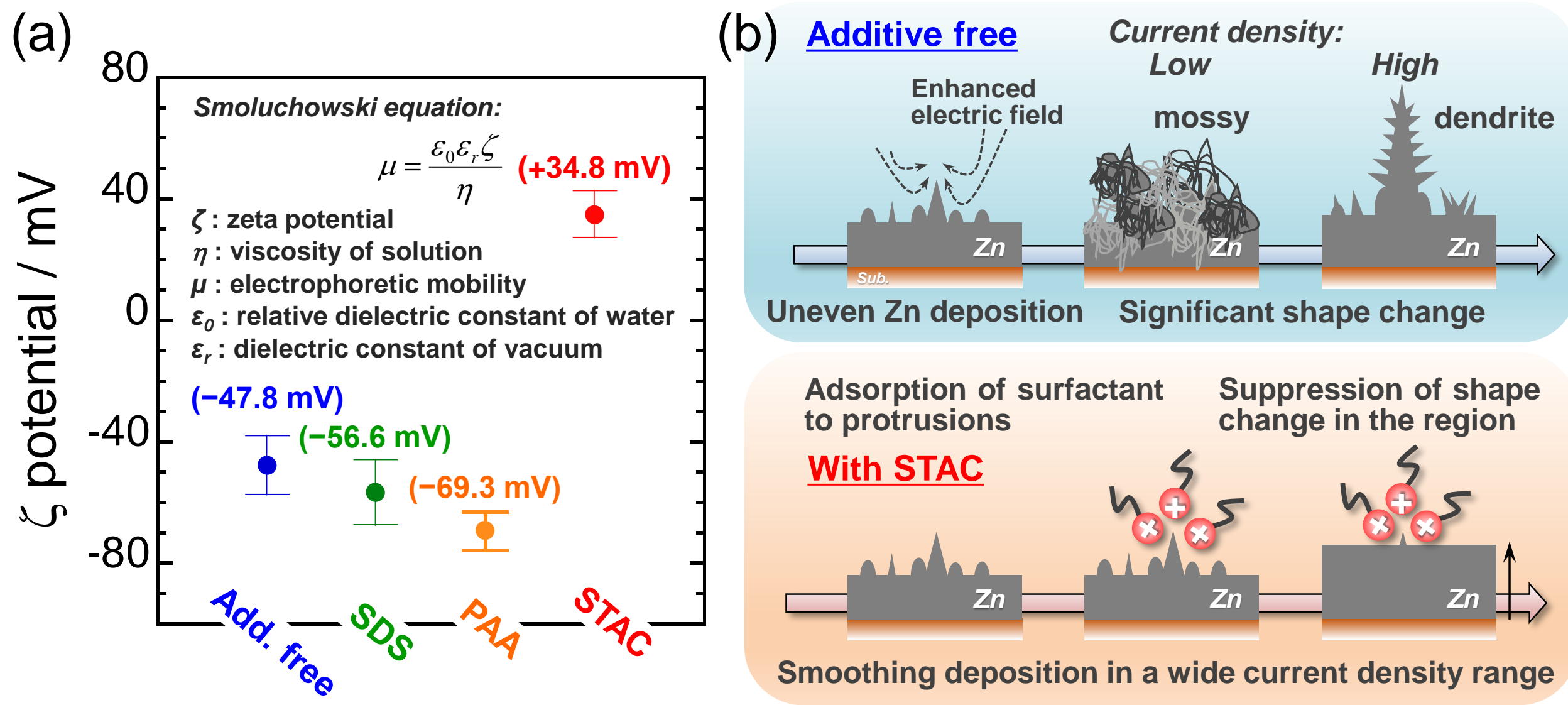

Smoothing deposition in a wide current density range

Figure 6. (a) Indicator for strength of electrical charge: Zeta potentials of PTFE particles (diameter: $200 \mathrm{~nm}$ ) granted by SDS, PAA, and STAC surfactants. For comparison, the potential in additive free electrolyte is also shown. (b) Proposed leveling mechanism of $\mathrm{Zn}$ deposition using STAC (cationic surfactant) under galvanostatic condition. 


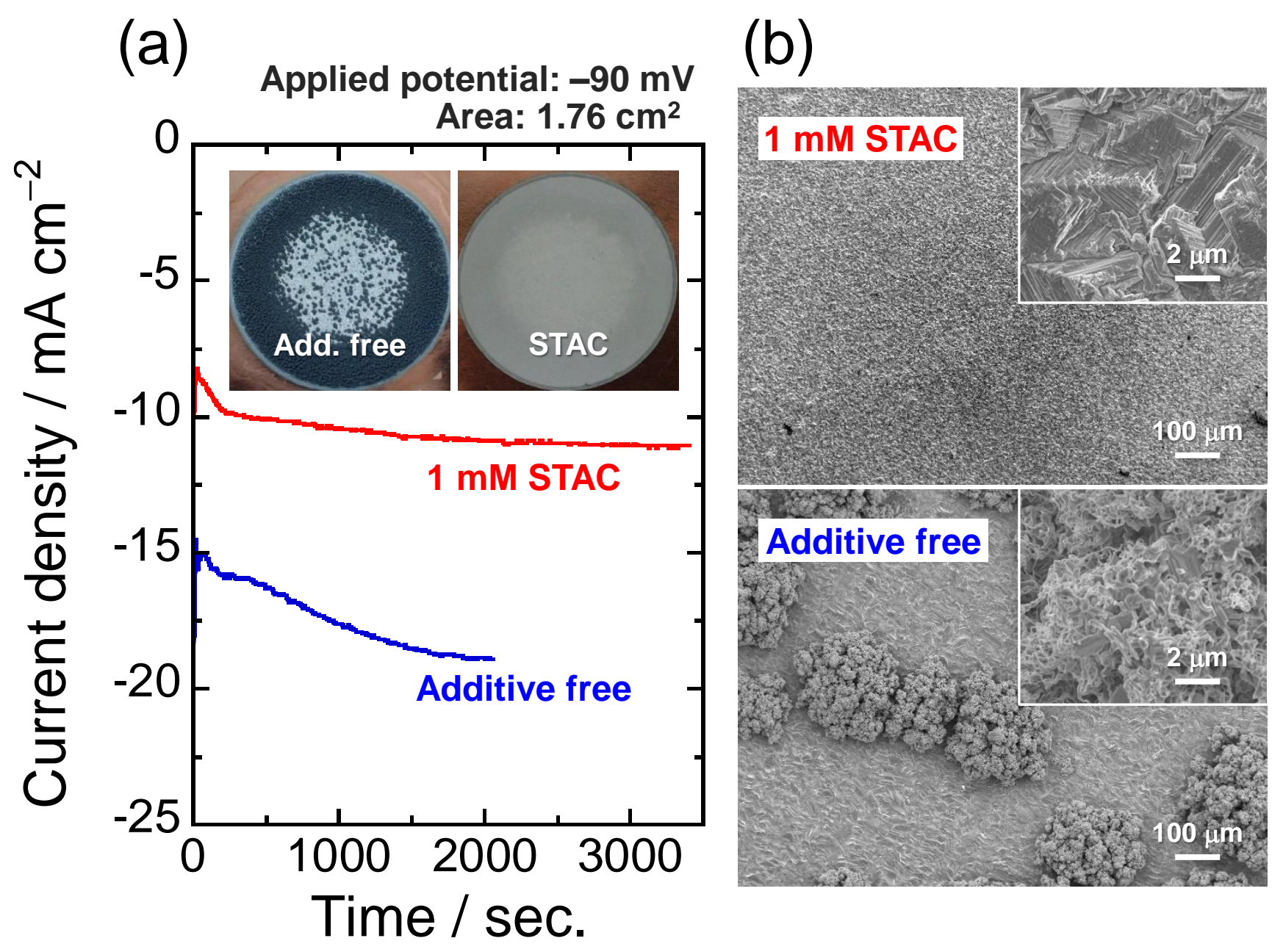

Figure 7. (a) Time dependence of current density for $\mathrm{Zn}$ electrodeposition in the constant potential of $-90 \mathrm{mV}$ vs. $\mathrm{Zn} / \mathrm{Zn}^{2+}$. (b) Surface FE-SEM images of the deposited $\mathrm{Zn}$. The constant electrolysis was finished when the charge amount for the electrodeposition reached to $10 \mathrm{~mA} \mathrm{~h} \mathrm{~cm}^{-2}$. Inset: photographs of deposits. 


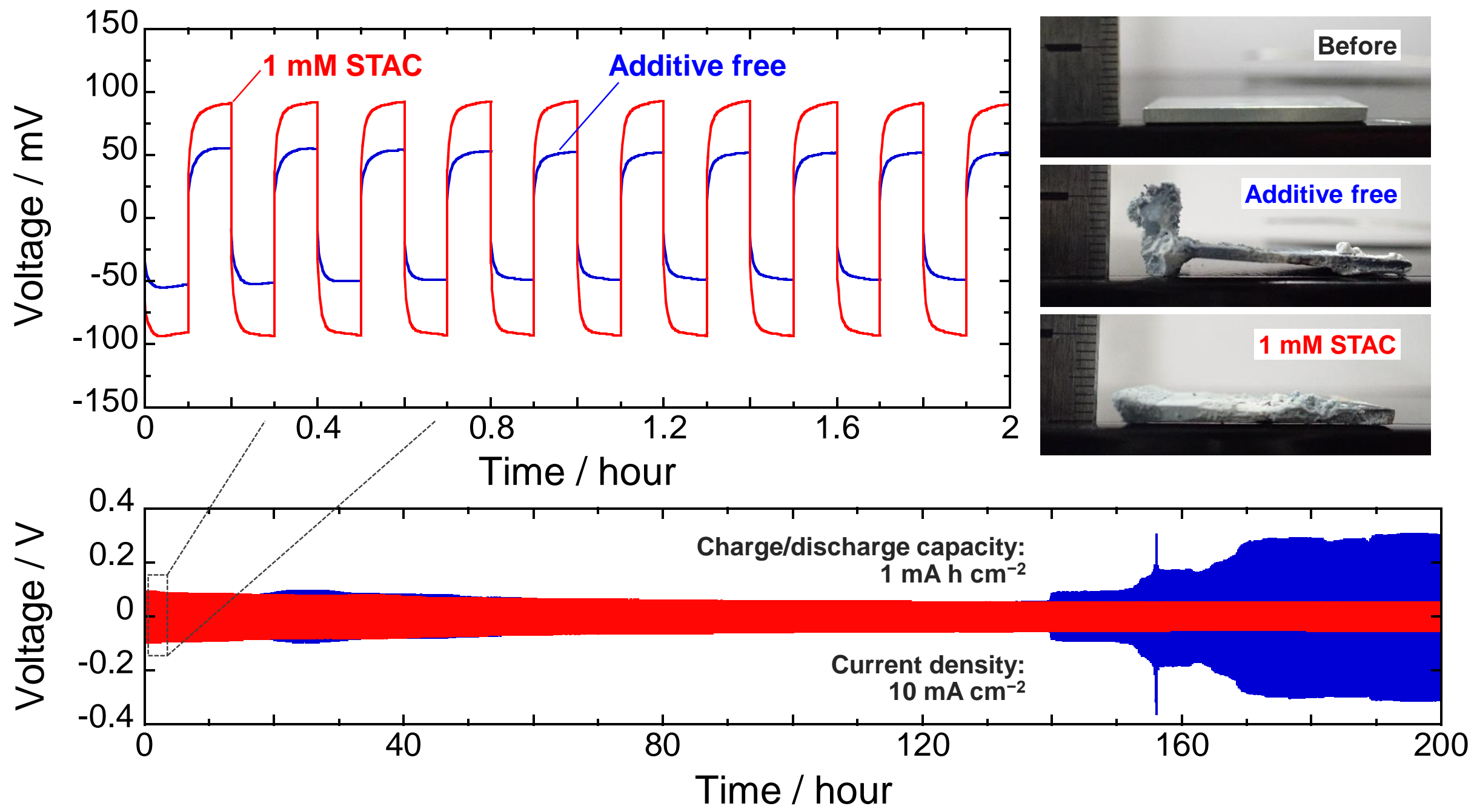

Figure 8. Long-term cycling of symmetric $\mathrm{Zn} \mid \mathrm{Zn}$ cells operated under a current density of $10 \mathrm{~mA} \mathrm{~cm}^{-2}$. The charge/discharge capacities were set to $1 \mathrm{~mA} \mathrm{~h} \mathrm{~cm}{ }^{-2}$. Inset: photographs of $\mathrm{Zn}$ metal sheets after the $\mathrm{Zn}$-deposition/stripping test. 


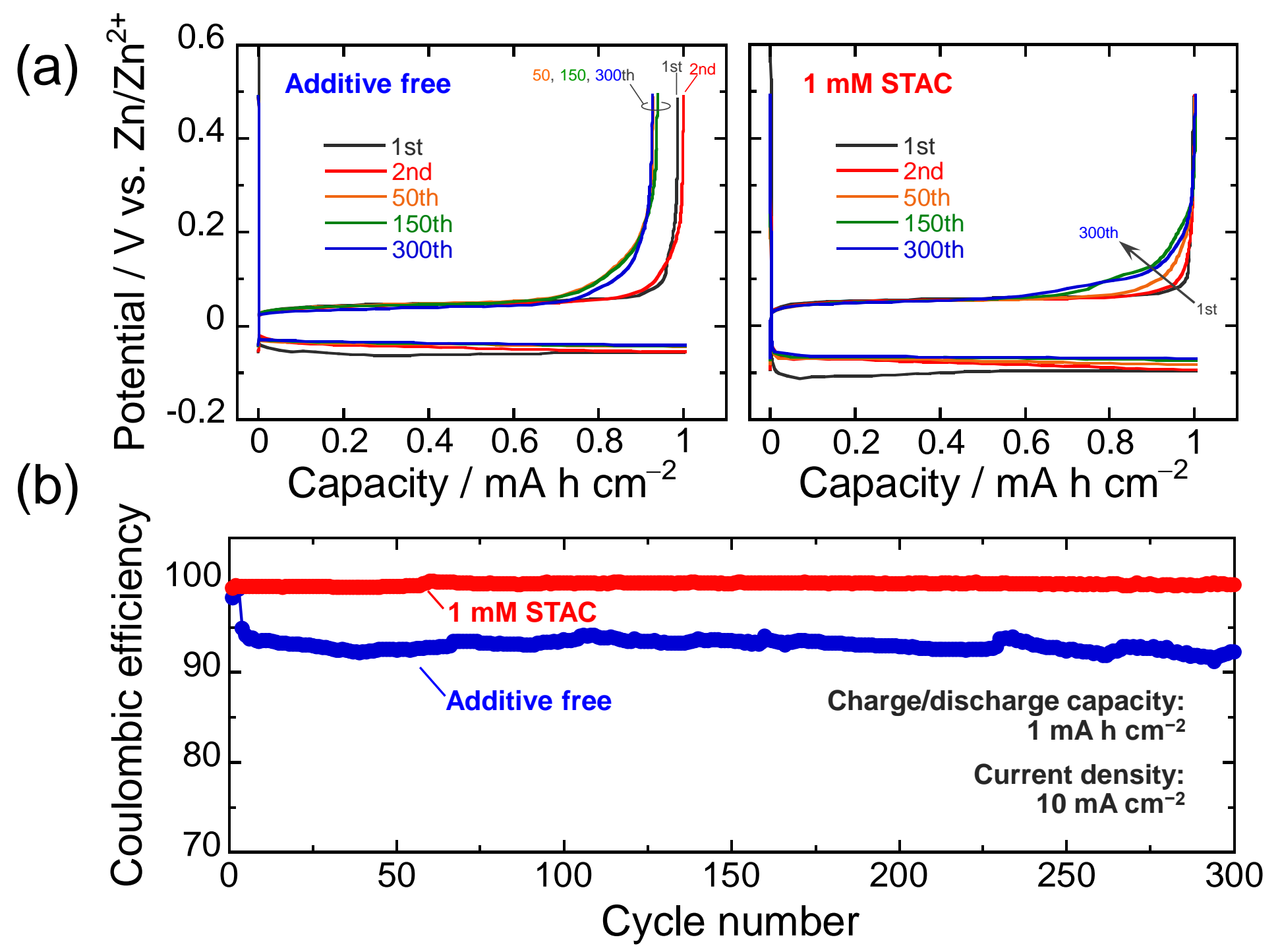

Figure 9. (a) Charge-discharge profiles and (b) dependence of Coulombic efficiency on cycle number for Zn-deposition/stripping in additive free and $1 \mathrm{mM}$ STAC containing electrolyte. 


\section{Electronic Supplementary Information (ESI)}

Morphology Control of Zinc Electrodeposition by Surfactant Addition for Alkaline-based Rechargeable Batteries

a Department of Materials Chemistry, Faculty of Engineering, Shinshu University ${ }^{b}$ Institute of Carbon Science and Technology, Faculty of Engineering, Shinshu University 4-17-1 Wakasato, Nagano 380-8553, Japan

Masahiro Shimizu*ab, Koichi Hiraharaa, Susumu Arai ${ }^{* a b}$ 


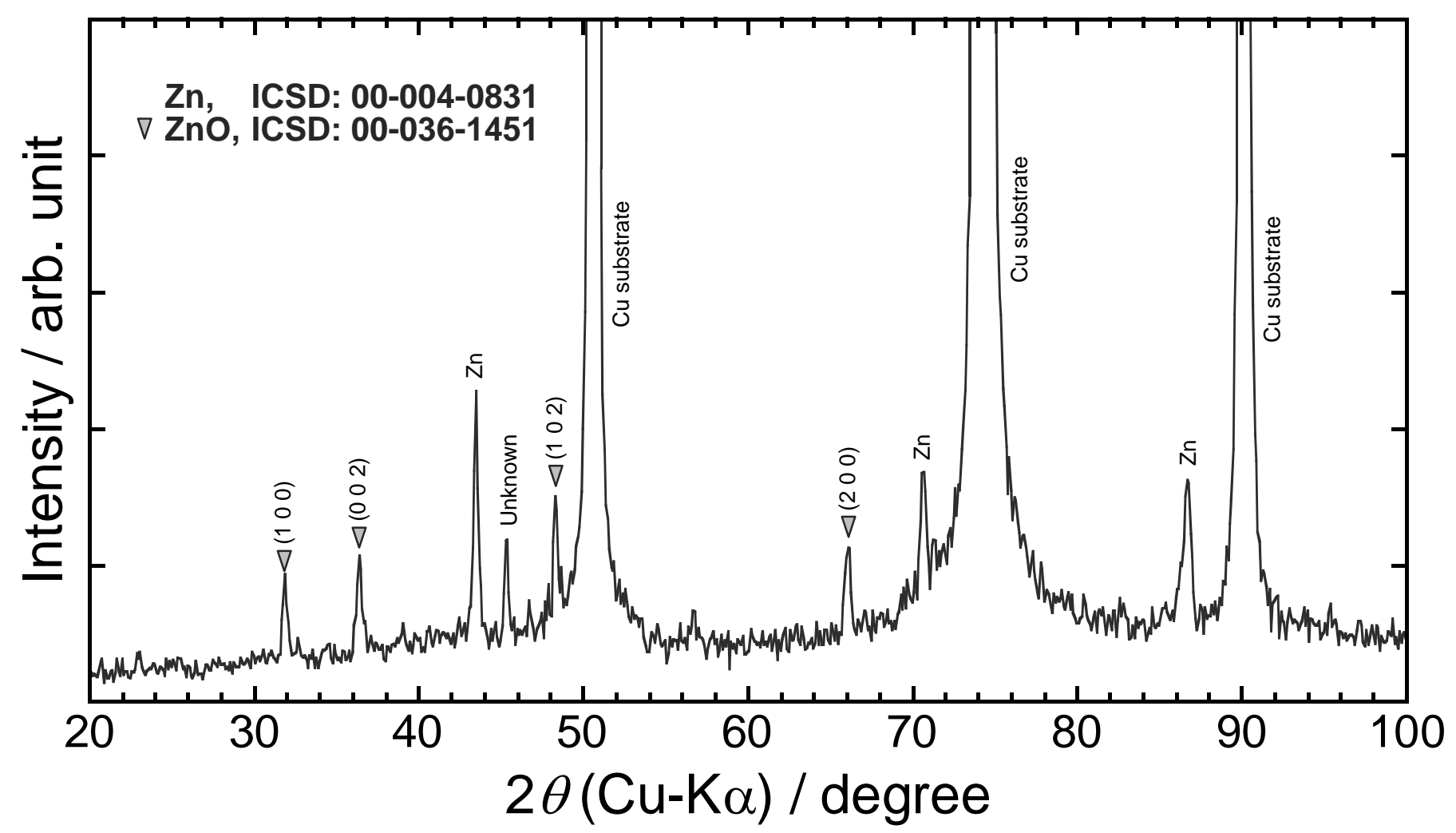

Figure S1. XRD pattern of a $\mathrm{Cu}$ substrate at the potential of $0.2 \mathrm{~V}$ vs. $\mathrm{Zn} / \mathrm{Zn}^{2+}$ in an additive free electrolyte. The cyclic voltammetry was stopped when sweeping to positive potential and the XRD measurement was conducted. Peaks associated with the formation of $\mathrm{ZnO}$ was confirmed, which indicates that the second oxidation peak is attributed to the formation of such passivation layer. 

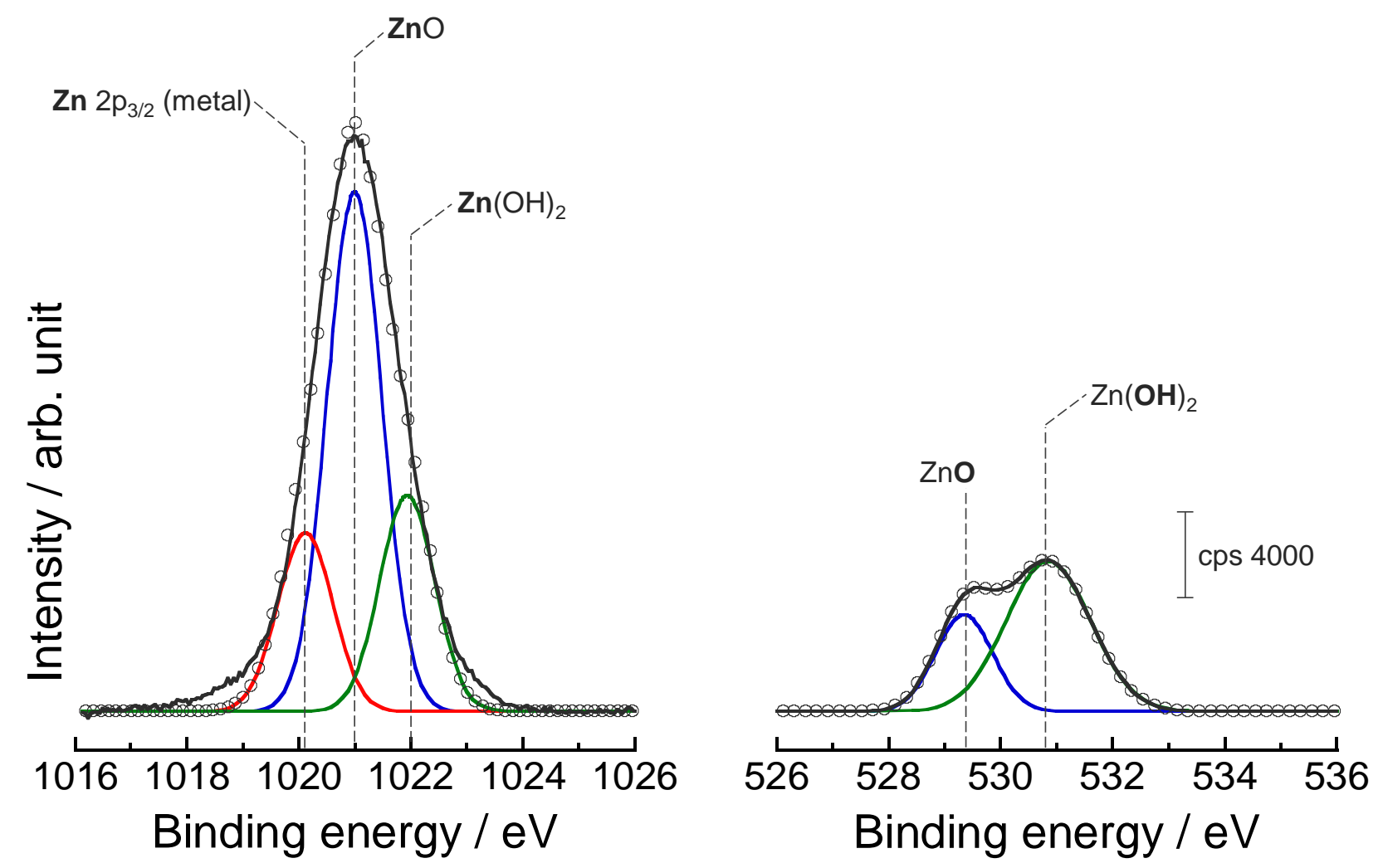

Figure S2. XPS spectra of (a) Zn 2p and (b) O 1s regions of Zn deposit obtained from a zincate solution (additive free). The spectra (recorded before Ar-etching) were deconvoluted into several components using a Gauss function. In the $\mathrm{Zn} 2 \mathrm{p}$ and $\mathrm{O} 1 \mathrm{~s}$ regions, the black, circle, red, blue, green lines correspond to the observed spectrum, the total spectrum, and the deconvoluted components of $\mathrm{Zn}$ metal, $\mathrm{ZnO}$, and $\mathrm{Zn}(\mathrm{OH})_{2}$. 

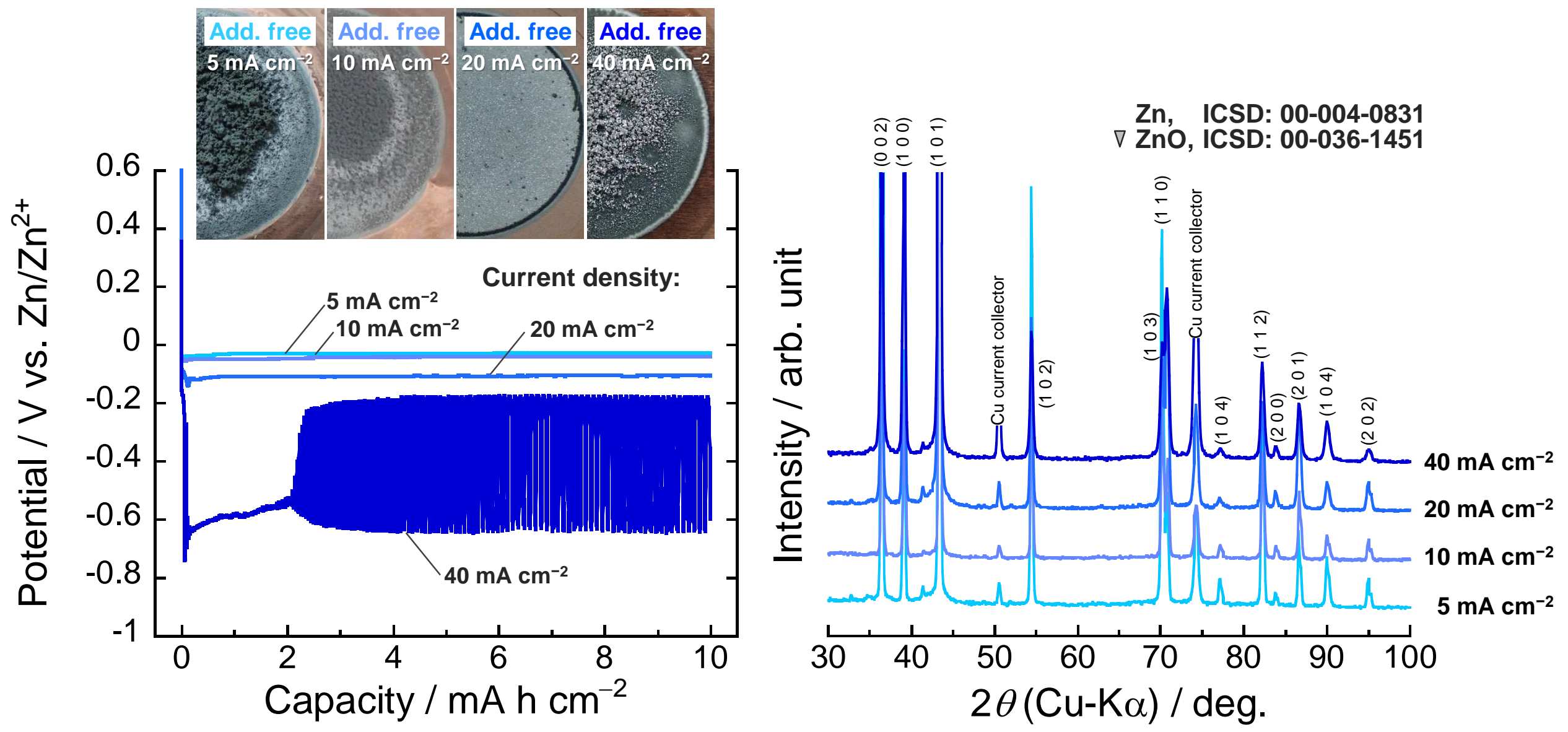

Figure S3. Electrochemical $\mathrm{Zn}$ deposition behaviors in an aqueous solution of $0.25 \mathrm{M} \mathrm{ZnO}+4 \mathrm{M} \mathrm{KOH}$ (additive free) under various current densities. The overpotential against equilibrium potential $\left(\mathrm{Zn}^{2+}+2 \mathrm{e}^{-} \rightarrow \mathrm{Zn}\right)$ in the respective condition was $28 \mathrm{mV}\left(5 \mathrm{~mA} \mathrm{~cm}^{-2}\right), 40 \mathrm{mV}\left(10 \mathrm{~mA} \mathrm{~cm}^{-2}\right), 107 \mathrm{mV}\left(20 \mathrm{~mA} \mathrm{~cm}^{-2}\right)$. 


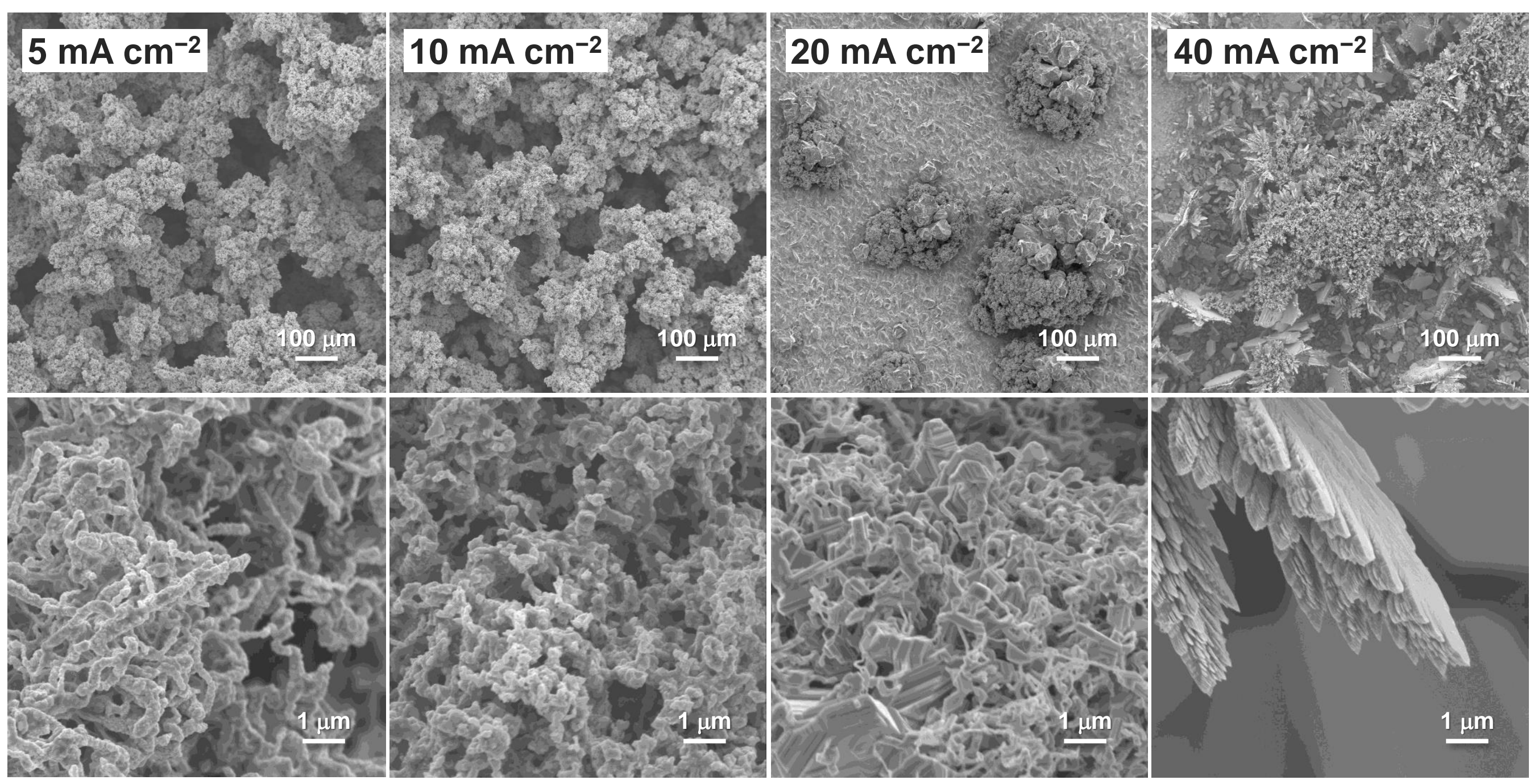

Figure S4. FE-SEM images of electrochemically grown $\mathrm{Zn}$ on a $\mathrm{Cu}$ substrate in a surfactant-free aqueous solution of $0.25 \mathrm{M} \mathrm{ZnO/4} \mathrm{M} \mathrm{KOH}$ under various current densities. Charge capacity was $10 \mathrm{~mA} \mathrm{~h} \mathrm{~cm}^{-2}$. 


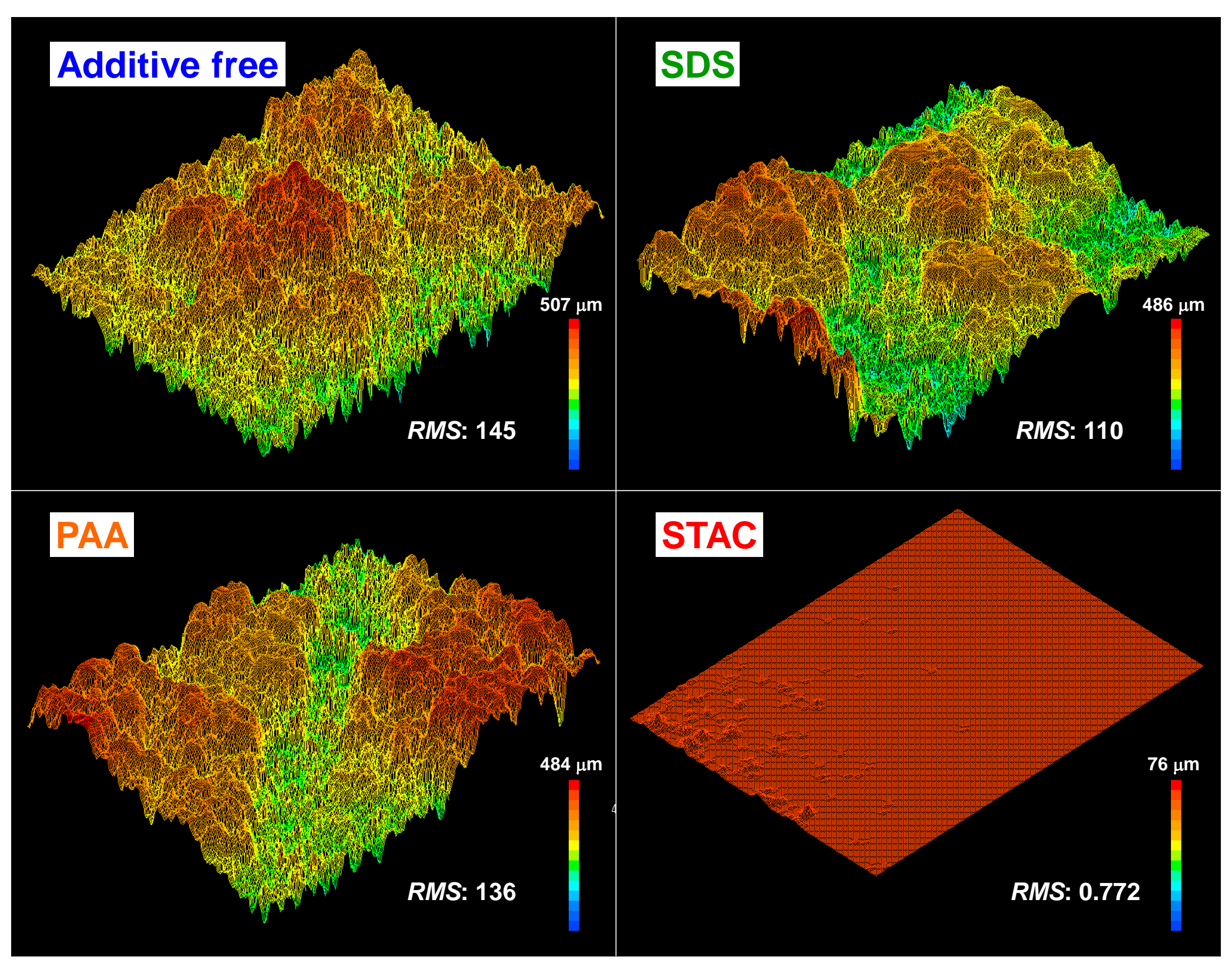

Figure S5. Three-dimensional height profiles of Zn morphologies deposited form various electrolyte with $1 \mathrm{mM}$ surfactant (additive free, SDS, PAA, and STAC). 


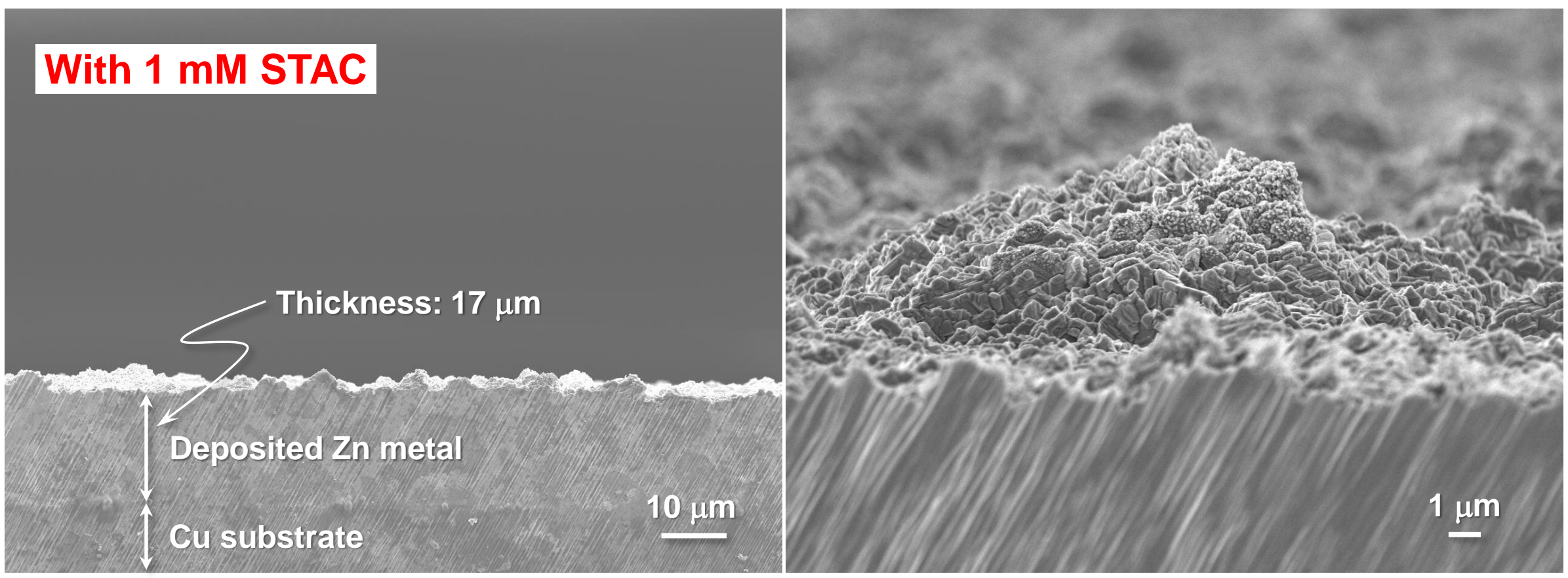

Figure S6. Cross-sectional FE-SEM images and enlarged views of $\mathrm{Zn}$ deposits obtained from an electrolyte solution containing $1 \mathrm{mM}$ STAC. The charge capacity corresponding to $\mathrm{Zn}$ deposition was $10 \mathrm{~mA} \mathrm{~h} \mathrm{~cm}$. Because the area of working electrode ( $\mathrm{Cu}$ current collector) was set to $1.7 \mathrm{~cm}^{2}$, the theoretical thickness of $\mathrm{Zn}$ deposit is $17 \mu \mathrm{m}$. It is noteworthy that the obtained thickness is good agreement with the theoretical one, which indicates that STAC surfactant with cationic charge acts as a leveling agent during $\mathrm{Zn}$ deposition. 

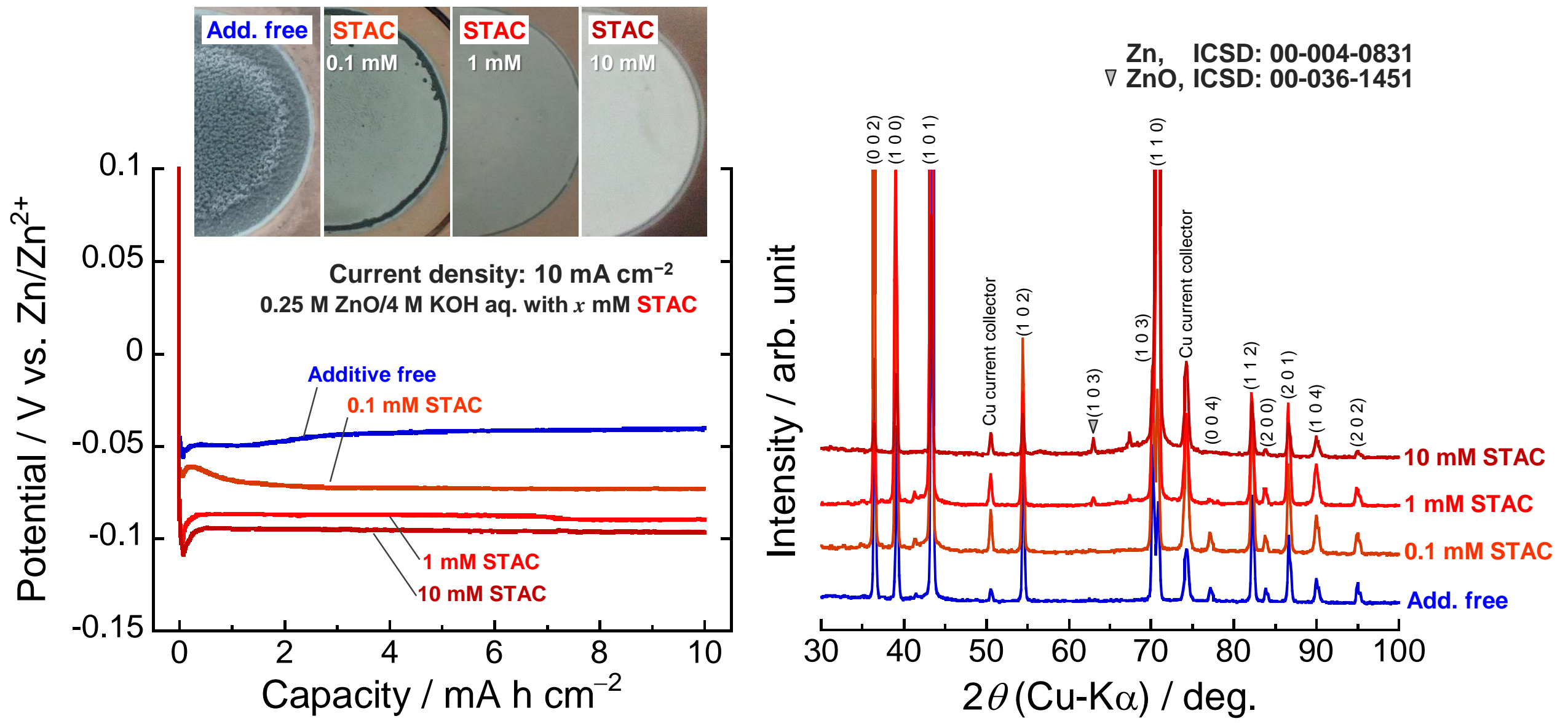

Figure S7. (a) STAC concentration dependence on charge ( $\mathrm{Zn}$ deposition) behavior in zincate solution. Current density was set to $10 \mathrm{~mA} \mathrm{~cm}{ }^{-2}$. (b) XRD patterns of the deposits obtained from the electrolytes. The overpotential against equilibrium potential $\left(\mathrm{Zn}^{2+}+2 \mathrm{e}^{-} \rightarrow \mathrm{Zn}\right)$ in the respective electrolyte was $40 \mathrm{mV}$ (additive free), $70 \mathrm{mV}$ (0.1 mM STAC), $90 \mathrm{mV}(1 \mathrm{mM})$, and $97 \mathrm{mV}(10 \mathrm{mM})$. 


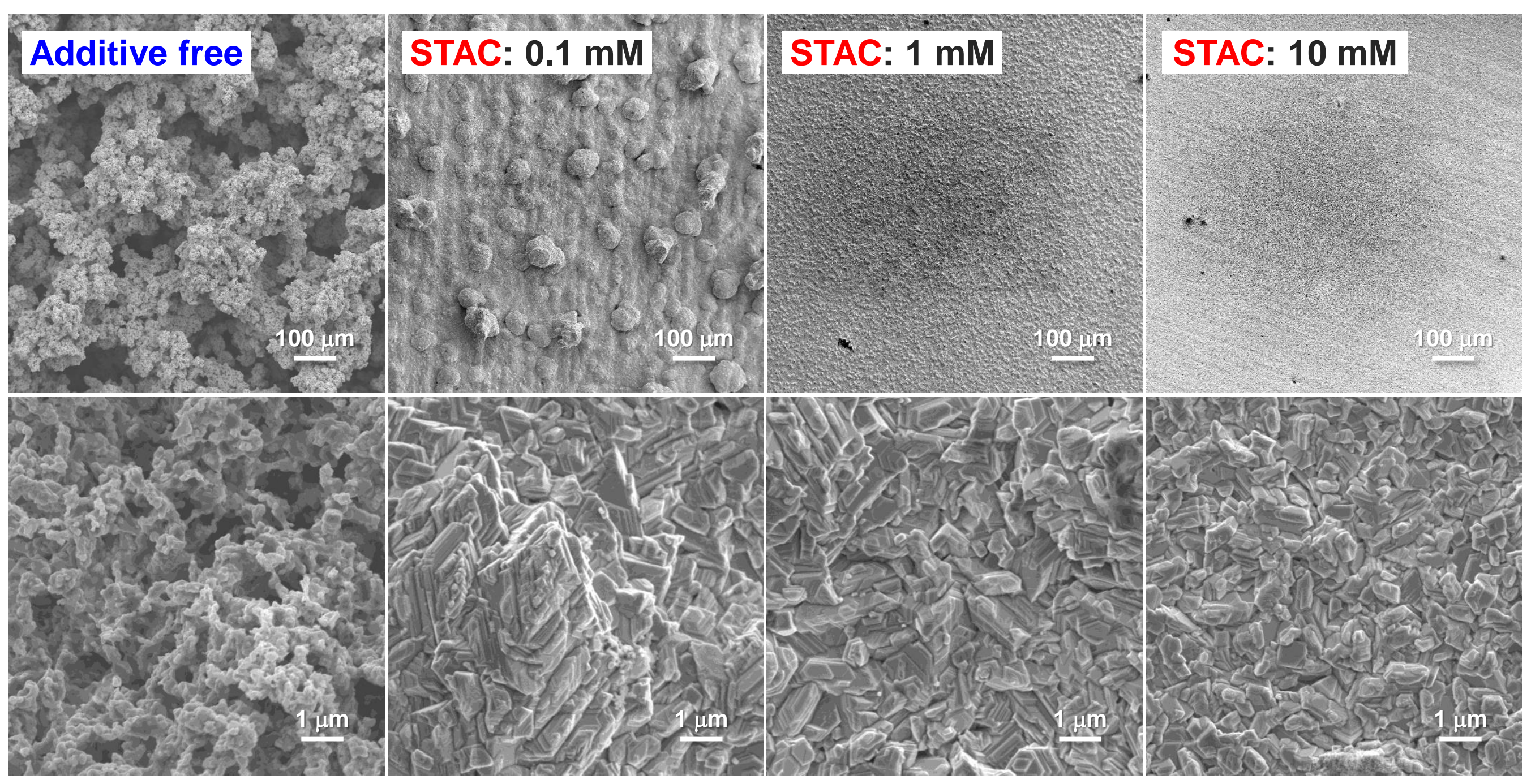

Figure S8. Influence of STAC concentration on Zn deposition morphology in an aqueous solution of $0.25 \mathrm{M} \mathrm{ZnO}+4 \mathrm{M} \mathrm{KOH}$. FE-SEM images of $\mathrm{Zn}$ deposited at

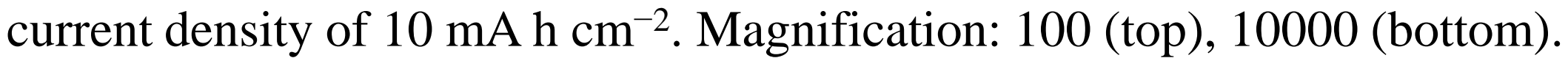




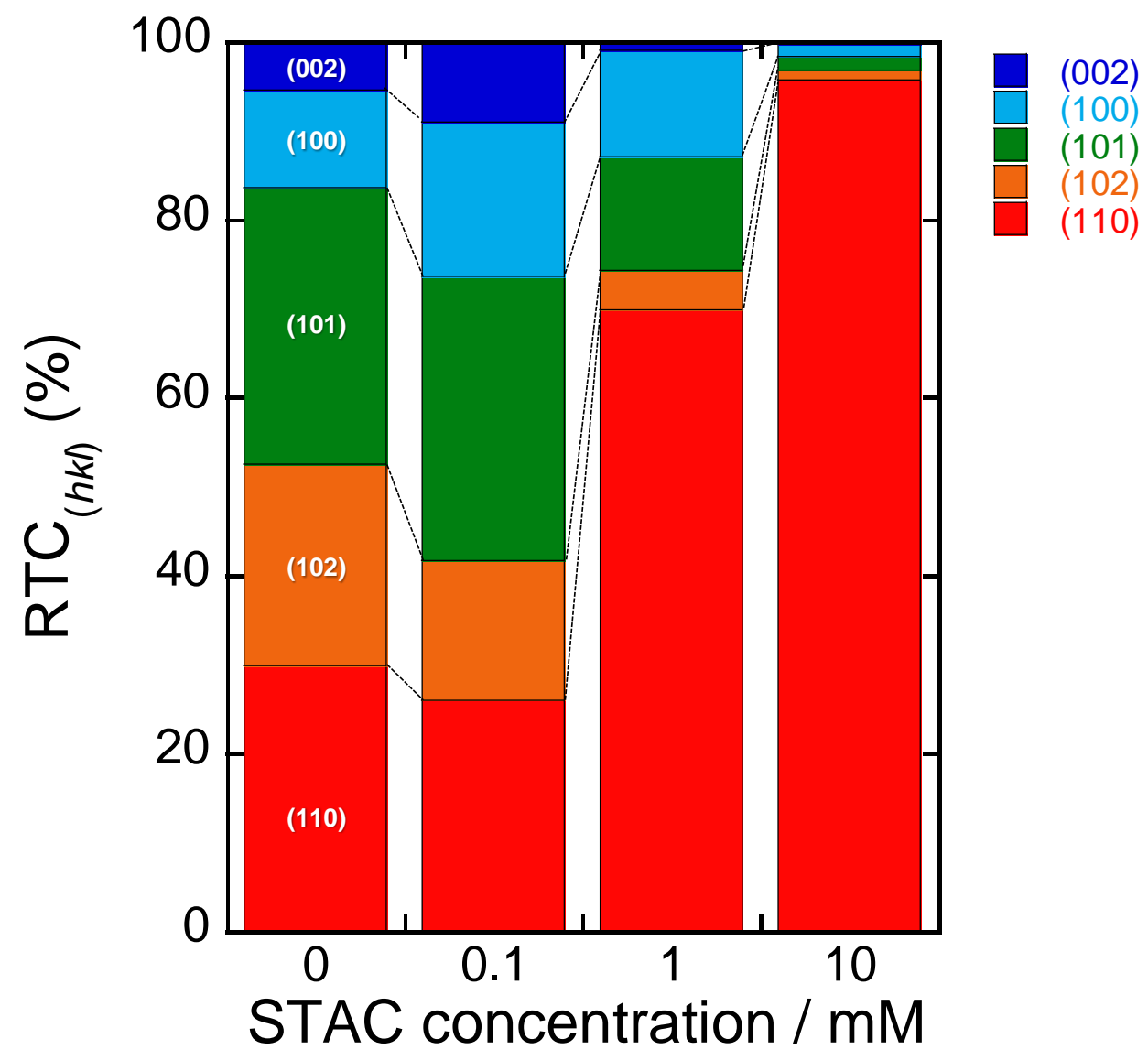

Figure S9. Variation in the relative texture coefficient for Zn (110), (002), (100), (101), and (102) diffraction peaks as a function of charge capacity in $0.25 \mathrm{M}$ $\mathrm{ZnO} / 4 \mathrm{M} \mathrm{KOH}$ with $x$ mmol L ${ }^{-1} \operatorname{STAC}(x=0,0.1,1,10)$. As a reference, commercially available $\mathrm{Zn}$ powder that is randomly orientated was used. 


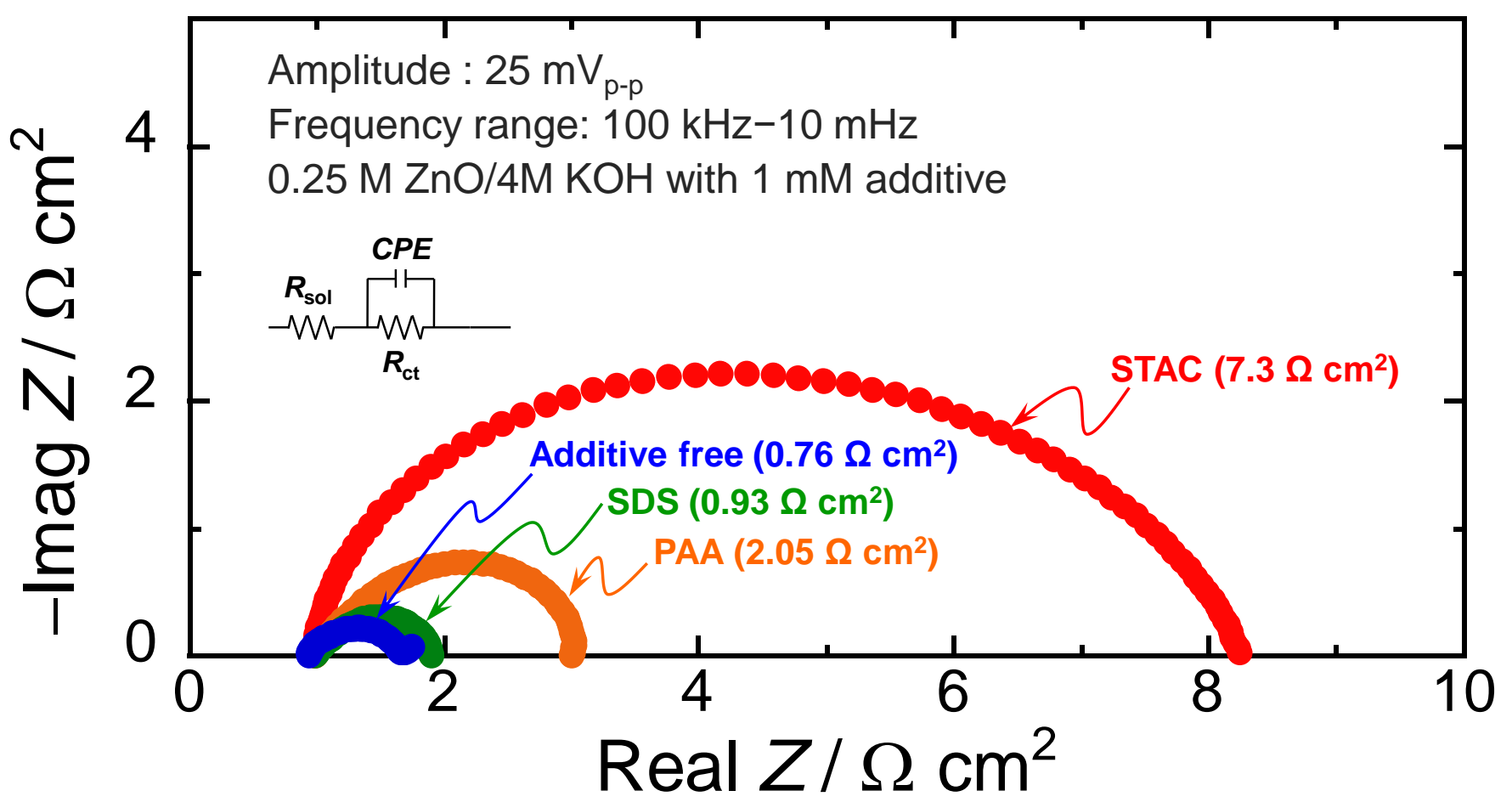

Figure S10. Nyquist plots of symmetric $\mathrm{Zn} \mid \mathrm{Zn}$ metal sheets cells in $0.25 \mathrm{M} \mathrm{ZnO/4}$ $\mathrm{M} \mathrm{KOH}$ with $1 \mathrm{mM}$ additive. Inset: the equivalent circuit for impedance analysis. SDS with a negative charge does not involve in charge transfer reaction associated with $\mathrm{Zn}$-deposition/dissolution and the resistance value depending the size of a semicircle is same degree in comparison with that in an additive free electrolyte. Although PAA has an influence on charge transfer, the resistance far smaller than that in $1 \mathrm{mM}$-SATC containing electrolyte. Thus, we consider that cationic surfactant plays a key role of leveling for $\mathrm{Zn}$ deposit. 

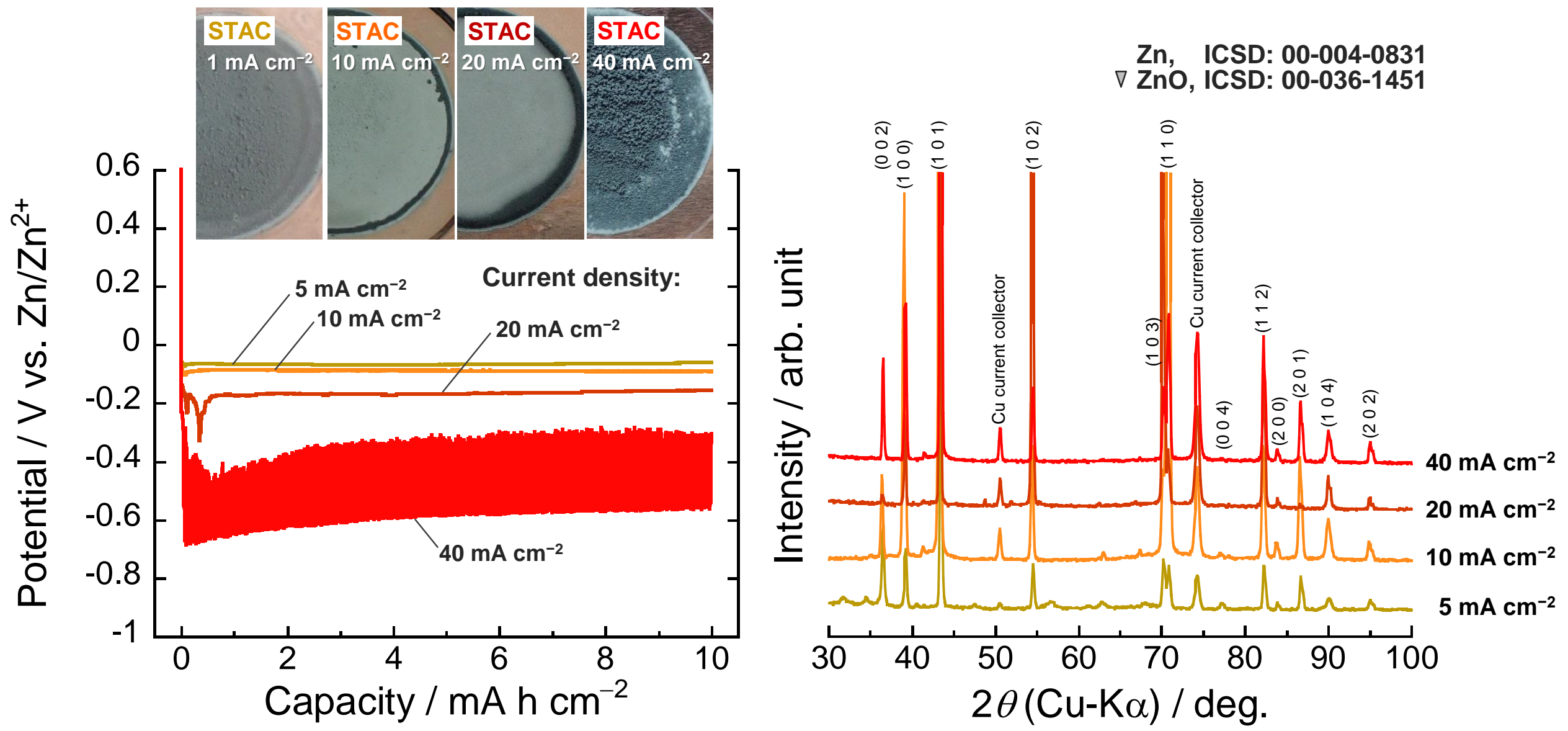

Figure S11. Electrochemical $\mathrm{Zn}$ deposition behaviors in an aqueous solution of $0.25 \mathrm{M} \mathrm{ZnO}+4 \mathrm{M} \mathrm{KOH}$ (additive free) with $1 \mathrm{mM}$ STAC under various current densities. The overpotential against equilibrium potential $\left(\mathrm{Zn}^{2+}+2 \mathrm{e}^{-} \rightarrow \mathrm{Zn}\right)$ in the respective condition was $63 \mathrm{mV}\left(5 \mathrm{~mA} \mathrm{~cm}^{-2}\right), 90 \mathrm{mV}\left(10 \mathrm{~mA} \mathrm{~cm}^{-2}\right), 157 \mathrm{mV}(20$ $\left.\mathrm{mA} \mathrm{cm}{ }^{-2}\right)$. 


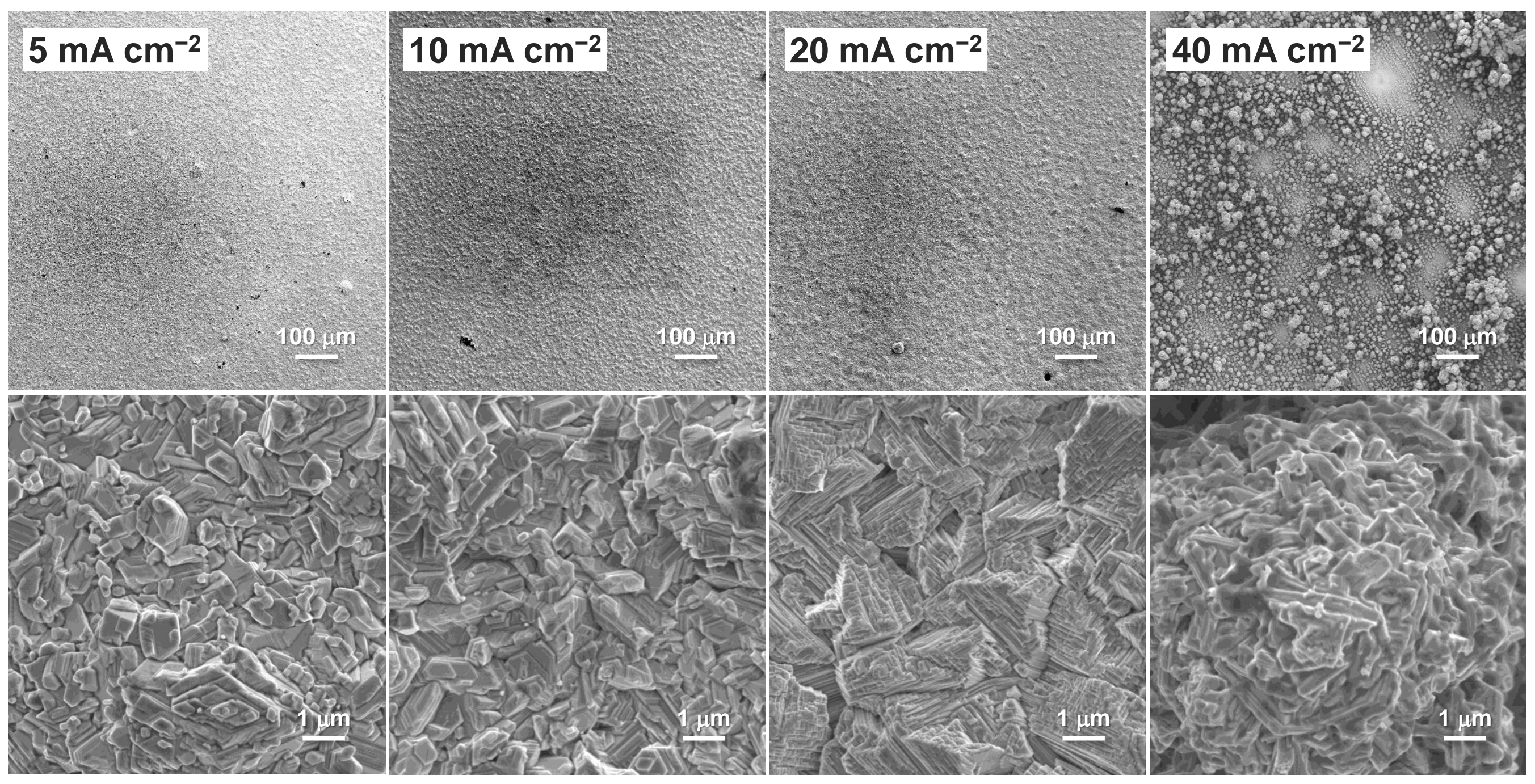

Figure S12. FE-SEM images of electrochemically grown $\mathrm{Zn}$ on a $\mathrm{Cu}$ substrate in an aqueous solution of $0.25 \mathrm{M} \mathrm{ZnO} / 4 \mathrm{M} \mathrm{KOH}$ with $1 \mathrm{mM}$ STAC under various current densities. Charge capacity was $10 \mathrm{~mA} \mathrm{~h} \mathrm{~cm}^{-2}$. 
(a)

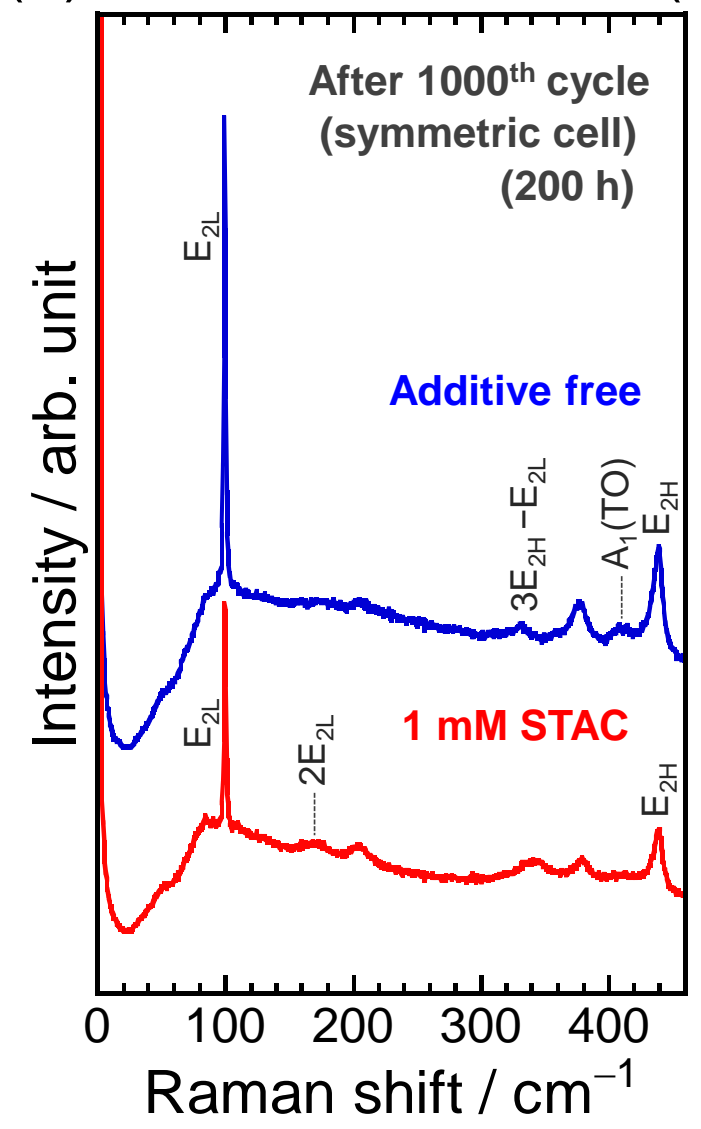

(b)

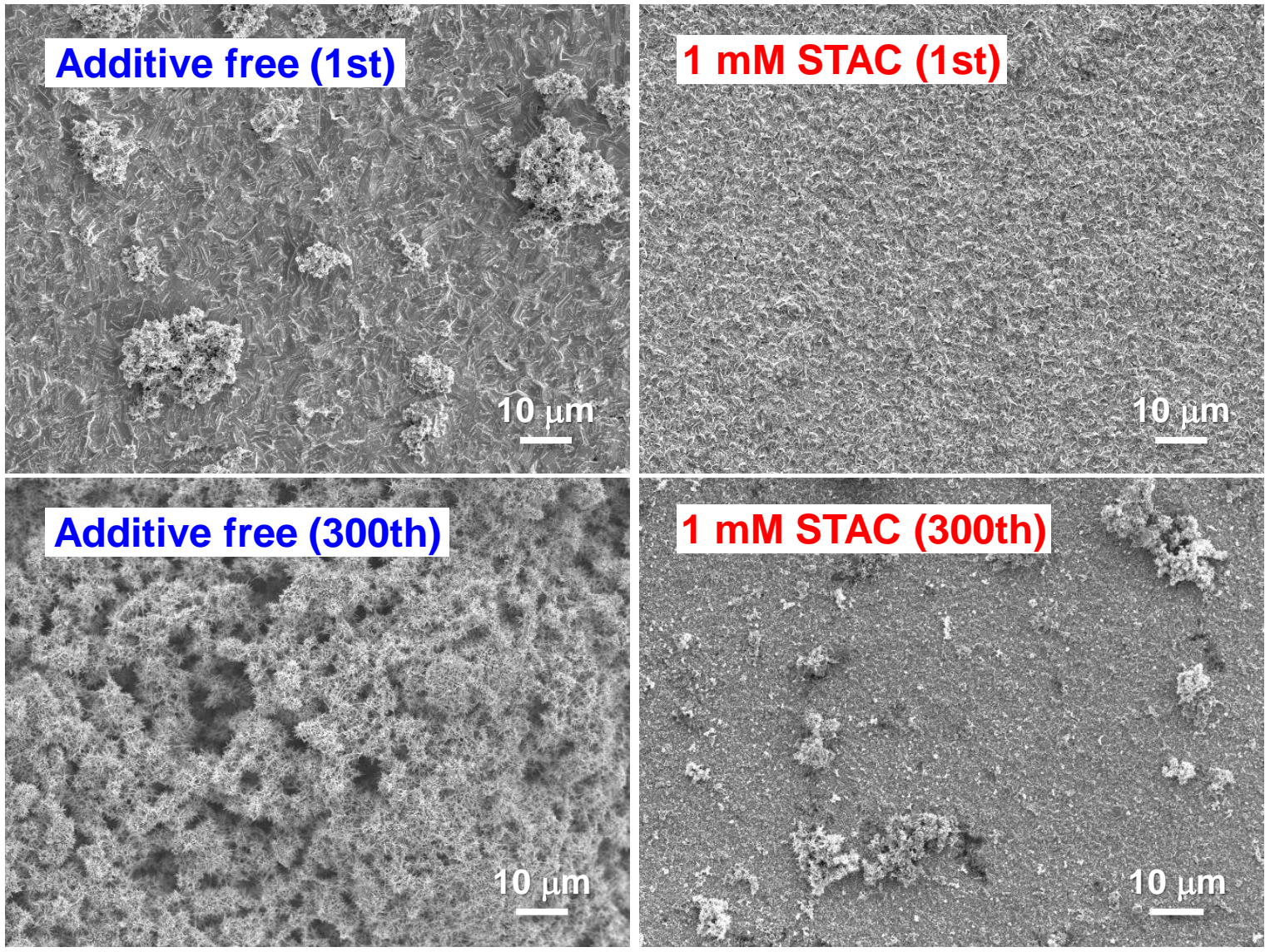

Figure S13. (a) Raman spectra of Zn metal sheets after 1000th (200 h) cycling in electrolyte solutions with and without $1 \mathrm{mM}$ STAC. (b) FE-SEM images of electrochemically grown $\mathrm{Zn}$ on a $\mathrm{Cu}$ substrate under various current densities. Charge (Zn deposition) capacity and current density was $1 \mathrm{~mA} \mathrm{~h} \mathrm{~cm}{ }^{-2}$ and $10 \mathrm{~mA}$ $\mathrm{cm}^{-2}$, respectively. 
Although the formation of $\mathrm{ZnO}$ was recognized regardless of the presence or absence of the additive, the band intensity associated with $\mathrm{ZnO}\left(100 \mathrm{~cm}^{-1} / \mathrm{E}_{2 \mathrm{~L}}, 165 \mathrm{~cm}^{-1} / 2 \mathrm{E}_{2 \mathrm{~L}}, 300\right.$ $\mathrm{cm}^{-1} / 3 \mathrm{E}_{2 \mathrm{H}}-\mathrm{E}_{2 \mathrm{~L}}, 417 \mathrm{~cm}^{-1} / \mathrm{A}_{1}(\mathrm{TO})$, and $\left.438 \mathrm{~cm}^{-1} / \mathrm{E}_{2 \mathrm{H}}\right)$ in the $1 \mathrm{mM}$-STAC containing electrolyte was weaker than that in the additive free electrolyte, which clearly showed that the addition of STAC effectively suppressed surface passivation of $\mathrm{Zn}$ metal. We therefore concluded that the sudden increase in overpotential at $156 \mathrm{~h}$ in an additive free electrolyte comes from the surface passivation by the accumulation of insulated $\mathrm{ZnO}$ on $\mathrm{Zn}$ metal surface. FE-SEM images of $\mathrm{Zn}$ grown on a $\mathrm{Cu}$ substrate after the first and 300th cycle in the respective electrolytes is displayed in Figure S11b. In the case of absence of any additive, $\mathrm{Zn}$ grew in mixture morphologies consisted of flat and mossy structures under a relatively low $\mathrm{Zn}$ deposition capacity of $1 \mathrm{~mA} \mathrm{~h} \mathrm{~cm}^{-2}$. In contrast, the addition of $1 \mathrm{mM}$ STAC delivered smooth Zn morphology without mossy structure. However, Zn deposits in the additive free electrolyte underwent a significant change in morphology: no flatstructured $\mathrm{Zn}$ was observed.

Reference

1) M. Wang, L. Jiang, E. J. Kim, S. H. Hahn, RSC Adv., 5 (2015) 87496-87503. 